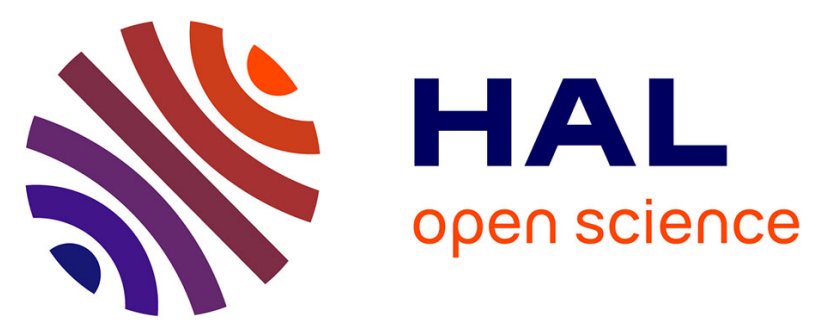

\title{
Robustness analysis of an uncertain computational model to predict well integrity for geologic $\mathrm{CO} 2$ sequestration
}

Christophe Desceliers, Christian Soize, Humberto Yáñez-Godoy, E. Houdu, O. Poupard

\section{To cite this version:}

Christophe Desceliers, Christian Soize, Humberto Yáñez-Godoy, E. Houdu, O. Poupard. Robustness analysis of an uncertain computational model to predict well integrity for geologic CO2 sequestration. Computational Geosciences, 2013, 17 (2), pp.307-323. 10.1007/s10596-012-9332-0 . hal-00757126

\section{HAL Id: hal-00757126 \\ https://hal.science/hal-00757126}

Submitted on 26 Nov 2012

HAL is a multi-disciplinary open access archive for the deposit and dissemination of scientific research documents, whether they are published or not. The documents may come from teaching and research institutions in France or abroad, or from public or private research centers.
L'archive ouverte pluridisciplinaire HAL, est destinée au dépôt et à la diffusion de documents scientifiques de niveau recherche, publiés ou non, émanant des établissements d'enseignement et de recherche français ou étrangers, des laboratoires publics ou privés. 


\title{
Robustness analysis of an uncertain computational model to predict well integrity for geologic $\mathrm{CO}_{2}$ sequestration
}

\author{
C. Desceliers · C. Soize · H. Yáñez-Godoy · E. Houdu • O. Poupard
}

Received: date / Accepted: date

\begin{abstract}
Geologic storage of $\mathrm{CO}_{2}$ must respond to demonstrations of safety, control and acceptability with authorities and public. The wells are essential elements of the storage system and constitute the only manmade intrusive element in the geologic systems. The role of containment of components of wells must then be ensured for hundreds of years, despite degradation mechanisms that affect their properties. Probabilistic approaches are used to take into account the uncertainties on the quantities of $\mathrm{CO}_{2}$ which migrate from the reservoir of $\mathrm{CO}_{2}$ towards the surface and towards the aquifer. Uncertainties are taken into account by using the generalized probabilistic approach which allows both the system-parameter uncertainties and the model uncertainties induced by modeling errors to be per-
\end{abstract}

\section{Desceliers}

Université Paris-Est, Laboratoire Modélisation et Simulation Multi-Echelle, MSME UMR 8208 CNRS, 5 bd Descartes, 77454 Marne-la-Vallée Cedex 2, France

E-mail: christophe.desceliers@univ-paris-est.fr

C. Soize

Université Paris-Est, Laboratoire Modélisation et Simulation Multi-Echelle, MSME UMR 8208 CNRS, 5 bd Descartes, 77454 Marne-la-Vallée Cedex 2, France

E-mail: christian.soize@univ-paris-est.fr

H. Yáñez-Godoy

OXAND S.A. 49 Avenue Franklin Roosevelt 77210 Avon,

France

E-mail: humberto.yanez@oxand.com

E. Houdu

OXAND S.A. 49 Avenue Franklin Roosevelt 77210 Avon,

France

E-mail: emmanuel.houdu@oxand.com

O. Poupard

OXAND S.A. 49 Avenue Franklin Roosevelt 77210 Avon, France

E-mail: olivier.poupard@oxand.com formed in the stochastic computational model. These probabilistic tools, applied to industrial projects, allow owners and operators to set up decisions and provide a strong support to long term safety demonstration with a high level of confidence, even in presence of uncertainties in the computational models.

Keywords Geologic $\mathrm{CO}_{2}$ sequestration . Well integrity · Uncertainty quantification · Parametric probabilistic approach · Nonparametric probabilistic approach - Modeling of uncertainties - Stochastic computational model $\cdot$ Degradation mechanisms

\section{Introduction}

Nowadays, the predictions of greenhouse gases emissions play a role becoming increasingly important. Authorities and industrials think about solutions to reduce their emissions. The Carbon Capture and Storage (CCS) technology constitutes one of the suitable technologies to reduce greenhouse gases emissions in the atmosphere. Even though CCS technology still brings intensive R\&D in the worldwide, a significant acceleration of in situ CCS experiments is observed to reach an industrial level. Pilots already exist worldwide but a lot of feasibility studies or ongoing projects have reached enough technical maturity to start a pilot phase.

The storage is now a major problem in the CCS chain, Capture - Transportation - Injection - Storage, without which no project will be able to emerge. The geologic storage of $\mathrm{CO}_{2}$ must respond to demonstrations of safety, control and acceptability with authorities and public. In most cases the evaluation of uncertainties is an essential component of these demonstrations. Uncertainties must be systematically studied and be inte- 
grated in a prediction model of a storage system. Their effects must be examined and taken into account for analyzing the performance of the storage system with a prediction model. It is necessary to take into account uncertainties in the computational models used to predict a long term (several hundred of years) behavior of storage systems elements.

Wells are made up of casings and cement sheaths and constitute the only intrusive and man-made element of the storage system in the geologic systems. The well is a preferential path for gas migration from the reservoir to the surface and/or potable aquifers. Because wells are part of the essential elements to consider in a study of well integrity and risks of $\mathrm{CO}_{2}$ migration during a geologic storage, it should be demonstrated that the well constitutes a safe barrier for $\mathrm{CO}_{2}$ confinement over long term. Indeed, it is of a paramount importance for a large acceptance of CCS technologies and their deployment. Moreover, due to the time scales involved, the integrity assessment of wells implies a number of specificities to the properties of the stored fluid and presents uncertainties related to the physical parameters and to the mechanisms involved.

This paper presents a robustness analysis of a computational model that analyzes the performance and the risks associated with well integrity on long term. It is well known that well degradation depends on several coupled physical phenomena $[1,5,10,13]$. Computational models have been developed in order to quantify possible gas migrations through a well $[5,10,13,25$, $32]$. The model presented in this paper is constructed by using a flow model in porous media and models of degradation in order to predict the behavior of constitutive elements of wells over time. Degradation affects the permeability of the system which has direct influence on the flow in the system. On the other hand, the gas flow in the media induces additional degradation: $\mathrm{CO}_{2}$ corrosion for casing and $\mathrm{CO}_{2}$ carbonation for cement. The complexity level of a complete 3-D multiphysic computational model of such mechanical system could be prohibitive for computational simulations over a long time period. In this paper, we have assumed the physical system is axisymmetric and each geological formation along the vertical axis of the well is modeled by a homogeneous medium. Moreover, due to a lack of experimental measurements, there exist uncertainties, not only on the initial conditions and on the boundary conditions (profile of the initial water pressure along the well, downhole storage pressure, flow conditions between cement the sheaths and the geological formations, etc.). There are also uncertainties in the model of the hydraulic conductivity matrices for the porous materials (coupling between the axial and radial intrinsic permeabilities). In this paper, as explained in Section 4, the uncertainties are taken into account in the computational model by using the parametric probabilistic approach for system-parameter uncertainties and the nonparametric probabilistic approach for model uncertainties induced by modeling errors (generalized probabilistic approach of uncertainties).

Section 2 is devoted to the presentation of the physical models used for constructing the mean computational model (nominal model) including the water and $\mathrm{CO}_{2}$ flow models, the different mechanisms of degradation and the damage model of intrinsic permeabilities. In Section 3, a synthetic equation representing the mean computational model is introduced and the different sources of uncertainties related to this mean model are listed. Section 4 deals with a short overview on the main concepts and methodologies for uncertainty quantification. This section has been introduced to help the reader to understand the probabilistic modeling carried out in Sections 5 and 6. In addition, some elements concerning stochastic solvers are given. The probabilistic modeling of uncertainties related to the mean computational model is presented in Section 5 while Section 6 deals with the effective construction of the probability distributions and their random generators for random variables and for random matrices involved in the probabilistic modeling of uncertainties. Section 7 is devoted to the application. Hereinafter, we present a sensitivity analysis for the model uncertainties. Finally, all the numerical values of the parameters of the mean computational model and of the stochastic computational model are summarized in two tables given in an Appendix.

\section{Physical models used for constructing the mean computational model}

This section is devoted to the presentation of the physical models used for constructing the mean computational model (nominal model) including the water and $\mathrm{CO}_{2}$ flow models in porous media, the different mechanisms of degradation and the damage model of intrinsic permeabilities. The objective of this mean computational model is to quantify the migration of $\mathrm{CO}_{2}$ through a well. Figure 1 shows how the different physical models are coupled to constitute the mean computational model. At each time step, the degradation of materials is computed and then is linked with flow computations in respecting the order of the sequences indicated in Fig. 1. The degradations directly affect the 


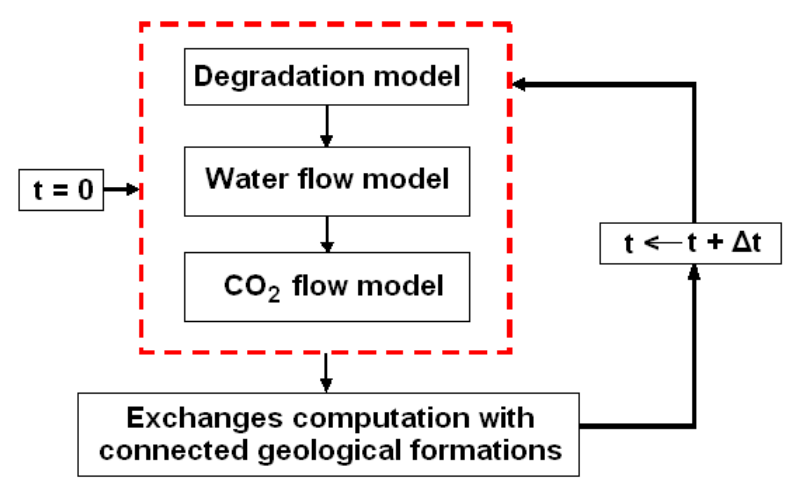

Fig. 1 Resolution principle of the mean computational model

permeability of the system and thus, alter the balance of pressure loading, that is to say the flow of water and $\mathrm{CO}_{2}$. The movement of $\mathrm{CO}_{2}$ in the system initiates the $\mathrm{CO}_{2}$ degradation. The following subsections describe the flow models in the porous media, the degradation mechanisms and the damage model of intrinsic permeabilities which are integrated into the mean computational model.

\subsection{Water and $\mathrm{CO}_{2}$ flow models}

Fig. 2 represents a schematic view of the system considered for this study. It includes stainless steel tubulars called casings (in black), cement sheaths that ensure the confinement of the holes between geology and the casings (in grey) and geological formations in contact with the well. Each well element (cement sheath, casing) and each near environment element (geological layers) are completely defined by their porosity, permeability and parameters of the Mualem-van Genuchten model. The well and the geologic layers (Fig. 2) occupy a domain $\Omega=\Omega^{1} \cup \ldots \cup \Omega^{n}$ in which the $\alpha$-th domain $\Omega^{\alpha}$ with $\alpha=1, \ldots, n$ is made up of geological formations and elements of the well (cement, casing, fluid). The generic point in $\Omega$ is written as $\mathbf{x}$. The mean physical model is constructed using a homogeneous equivalent flow model for each domain $\Omega_{\alpha}$. The medium occupying the $\alpha$-th domain $\Omega^{\alpha}$ is then modeled with an equivalent porous medium. An equivalent porous medium is also used for domains that are lightly porous or not porous, such as the interior of the well. In this case, the parameters of the constitutive equations are adjusted such that the flow is very small. In this paper, it is also assumed that, at the scale of the well, the diffusion is small with respect to convection for the gradients of pressure. The solid phase is assumed to be in thermodynamic equilibrium with the solution inside the pores. This solution is made up of a wetting phase (w) and of a non-wetting phase (nw). Let $\mathbf{v}_{\alpha}^{\mathrm{w}}(\mathbf{x}, t)$ and $\mathbf{v}_{\alpha}^{\mathrm{nw}}(\mathbf{x}, t)$ be the vectors of the average velocity fields of the wetting phase and of the non-wetting phase in the $\alpha$-th domain $\Omega^{\alpha}$. Both phases are assumed to be immiscible and they satisfy the following mass conversation equations for the two phases $[7,8,12,15]$ in the $\alpha$-th domain $\Omega^{\alpha}$,

$\frac{\partial\left(\rho_{\alpha}^{\mathrm{w}} \eta_{\alpha} s_{\alpha}^{\mathrm{w}}\right)}{\partial t}+\operatorname{div}\left(\rho_{\alpha}^{\mathrm{w}} \mathbf{v}_{\alpha}^{\mathrm{w}}\right)=0$,

$\frac{\partial\left(\rho_{\alpha}^{\mathrm{nw}} \eta_{\alpha} s_{\alpha}^{\mathrm{nw}}\right)}{\partial t}+\operatorname{div}\left(\rho_{\alpha}^{\mathrm{nw}} \mathbf{v}_{\alpha}^{\mathrm{nw}}\right)=0$.

In the previous equations, $\rho_{\alpha}^{\mathrm{w}}(\mathbf{x}, t)$ and $\rho_{\alpha}^{\mathrm{nw}}(\mathbf{x}, t)$ are the mass of water and the mass of gas, per volume unit, $\eta_{\alpha}$ is the porosity, $s_{\alpha}^{\mathrm{w}}(\mathbf{x}, t)$ and $s_{\alpha}^{\mathrm{nw}}(\mathbf{x}, t)$ are the water and gas saturations such that

$s_{\alpha}^{\mathrm{w}}(\mathbf{x}, t)+s_{\alpha}^{\mathrm{nw}}(\mathbf{x}, t)=1$.

The pressure fields $p_{\alpha}^{\mathrm{w}}(\mathbf{x}, t)$ and $p_{\alpha}^{\mathrm{nw}}(\mathbf{x}, t)$ in the wetting phase and in the non-wetting phase of the $\alpha$-th domain $\Omega^{\alpha}$ satisfy the following Darcy equations,

$\mathbf{v}_{\alpha}^{\mathrm{w}}=-\frac{k_{\mathrm{r}, \alpha}^{\mathrm{w}}}{\mu_{\alpha}^{\mathrm{w}}}\left[\underline{K}_{\alpha}\right]\left(\operatorname{grad} p_{\alpha}^{\mathrm{w}}-\rho_{\alpha}^{\mathrm{w}} \mathbf{g}\right)$,

$\mathbf{v}_{\alpha}^{\mathrm{nw}}=-\frac{k_{\mathrm{r}, \alpha}^{\mathrm{nw}}}{\mu_{\alpha}^{\mathrm{nw}}}\left[\underline{K}_{\alpha}\right]\left(\operatorname{grad} p_{\alpha}^{\mathrm{nw}}+\left(\rho_{\alpha}^{\mathrm{w}}-\rho_{\alpha}^{\mathrm{nw}}\right) \mathbf{g}\right)$.

In these equations, $k_{\mathrm{r}, \alpha}^{\mathrm{w}}(\mathbf{x}, t)$ and $k_{\mathrm{r}, \alpha}^{\mathrm{nw}}(\mathbf{x}, t)$ are the two relative permeabilities, $\mu_{\alpha}^{\mathrm{w}}$ and $\mu_{\alpha}^{\mathrm{nw}}$ are the two viscosities and $\mathbf{g}$ is the gravity acceleration vector. These equations involve an intrinsic permeability matrix denoted by $\left[\underline{K}_{\alpha}(t)\right]$ which is a positive-definite symmetric $(2 \times 2)$ real matrix. Consequently, the intrinsic and relative permeabilities are both taken into account.

Let $s_{r, \alpha}^{\mathrm{w}}$ be the irreducible water saturation, $\rho$ be the water mass density, $p_{e c, \alpha}$ be the capillary entry pressure, $R$ be the gas constant, $\mathcal{M}$ be the gas molar mass in the non-wetting phase and $T_{\alpha}$ be the local temperature. It is assumed that the hydraulic properties are described using the pore size distribution model of Mualem for the hydraulic conductivity,

$$
\begin{aligned}
& p_{\alpha}^{\mathrm{nw}}(\mathbf{x}, t)-p_{\alpha}^{\mathrm{w}}(\mathbf{x}, t)=p_{\mathrm{ec}, \alpha}\left(\left(\theta_{\alpha}(\mathbf{x}, t)\right)^{-M_{\alpha}}-1\right)^{-N_{\alpha}}, \\
& p_{\alpha}^{\mathrm{nw}}(\mathbf{x}, t)=\frac{\rho_{\alpha}^{\mathrm{nw}}(\mathbf{x}, t) \rho}{\rho \eta_{\alpha}-\rho_{\alpha}^{\mathrm{w}}(\mathbf{x}, t)} \frac{R T_{\alpha}}{\mathcal{M}}
\end{aligned}
$$

where $M_{\alpha}, N_{\alpha}$ are two given parameters obtained from experimental measurements and where

$\theta_{\alpha}(\mathbf{x}, t)=\left(s_{\alpha}^{\mathrm{w}}(\mathbf{x}, t)-s_{r, \alpha}^{\mathrm{w}}\right) /\left(1-s_{r, \alpha}^{\mathrm{w}}\right)$, 
The Muale model is used in combination with a water retention model introduced by van Genuchten and which is written as

$k_{r, \alpha}^{\mathrm{w}}(\mathbf{x}, t)=\left(\theta_{\alpha}(\mathbf{x}, t)\right)^{\frac{1}{2}}\left(1-\left(1-\left(\theta_{\alpha}(\mathbf{x}, t)\right)^{\frac{1}{M_{\alpha}}}\right)^{M_{\alpha}}\right)^{2}$,

$k_{r, \alpha}^{\mathrm{nw}}(\mathbf{x}, t)=\left(1-\theta_{\alpha}(\mathbf{x}, t)\right)^{\frac{1}{2}}\left(1-\left(\theta_{\alpha}(\mathbf{x}, t)\right)^{\frac{1}{M_{\alpha}}}\right)^{2 M_{\alpha}}$.

Consequently, Eqs. (6) to (10) are used for the constitutive equations of the materials [31]. It should be noted that the use of an ideal gas law in Eq. (7) rather than some EOS for CO2 density in critical conditions induces modeling errors. More generally, as it will be explained in Section 4, all the modeling errors induced by the model simplifications with respect to a more advanced model, will be taken into account in implementing a probabilistic model of uncertainties (Sections 5 and 6 ).

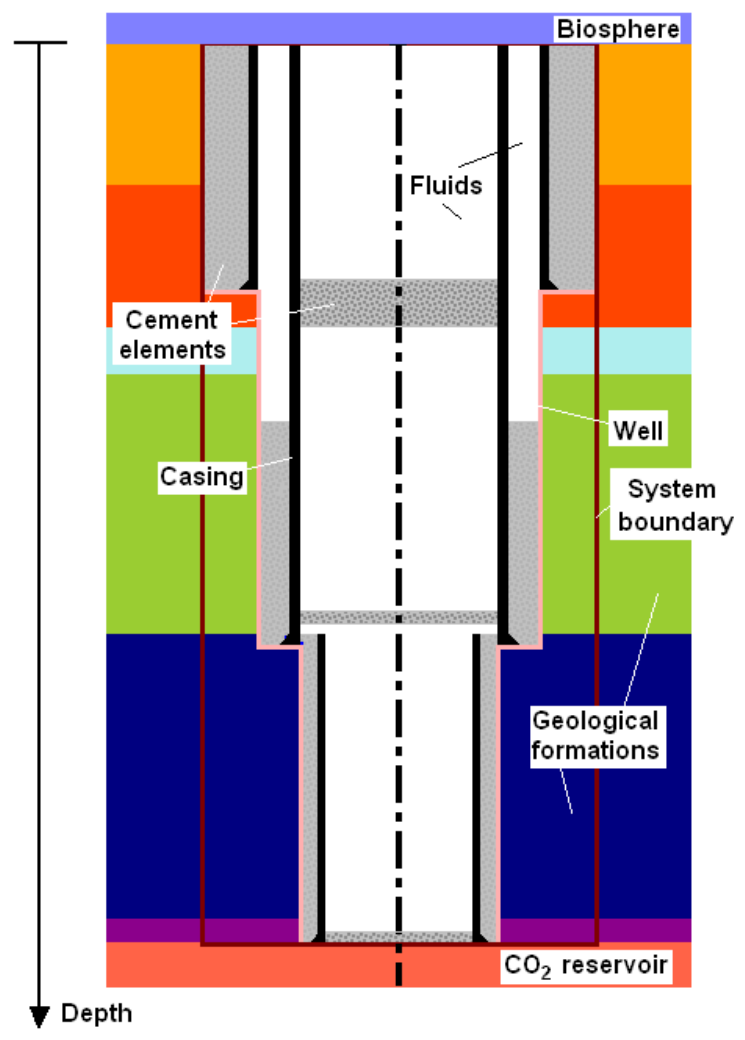

Fig. 2 Well and geological formations

\subsection{Degradation mechanisms}

The aging models enable to estimate the evolution of components properties over time due to environment of the well. Two models are considered for describing the degradation mechanisms of the carbon steel tubes and of the cement-based materials. These two models are devoted to the cement leaching and the casing corrosion $[1,5,13]$. Cement-based materials are reactive porous media in which solid phases are in thermodynamic equilibrium with the surrounding pore solution chemistry. An acidic attack of the cement-based materials takes place when they are in contact with acidic aqueous solutions.

The leaching process of hydrates is essentially due to the chemical activity and to the difference of composition between the water in contact within the cement and the pore solution inside the material. As a consequence, ions move out from the cement and subsequent dissolutions of cement minerals occur (mainly hydrates: Portlandite, CSH). Such a cement leaching increases the porosity and the permeability. Consequently, the compressive strength decreases.

Nevertheless, the casing corrosion is the main degradation process which must be considered when the long term integrity performance of the well is analyzed. It occurs once the cement leaching is completed, mostly as a generalized uniform corrosion at the casing surface but also as a pitting corrosion due to the presence of chlorides. It should be noted that corrosion by $\mathrm{CO}_{2}$ is more significant in presence of dissolved $\mathrm{CO}_{2}$ in the water but it becomes insignificant for dry supercritical flows.

Let $a_{\text {in, } \alpha}$ and $a_{\text {out, } \alpha}$ be the inner and outer leaching (uniform or pitting) corrosion rates and let $F_{\text {in, } \alpha}$ and $F_{\text {out }, \alpha}$ be the inner and outer degradation factors of the in the $\alpha$-th domain $\Omega^{\alpha}$.

\subsection{Damage model of intrinsic permeabilities}

In this section, we present the deterministic model of damage intrinsic permeability for the cement and steel materials developed in $[20,21,9,16,23]$. In the $\alpha$-th domain $\Omega^{\alpha}$, the intrinsic radial and axial permeabilities are denoted by $k_{\text {radial }, \alpha}$ and $k_{\text {axial }, \alpha}$.

\subsubsection{Cement degradation}

For each domain $\Omega^{\alpha}$ made up of cement material, the diffusion of aggressive elements controls the degradation reaction of cement. Consequently a simple model for the cement degradation consists in modeling the advance of two leaching fronts (the internal advance and the external advance) by two fonctions $e_{\text {in } \alpha}(t)=$ $a_{\text {in }, \alpha} \sqrt{t}$ and $e_{\text {out }, \alpha}(t)=a_{\text {out }, \alpha} \sqrt{t}$. Behind the leaching fronts $e_{\mathrm{in}, \alpha}(t)$ and $e_{\mathrm{out}, \alpha}(t)$, the intrinsic permeability is multiplied respectively by the internal degradation factor $F_{\text {in, } \alpha}$ and by the external degradation factor $F_{\text {out }, \alpha}$ 
(see Fig. 3). It should be noted that each degradation

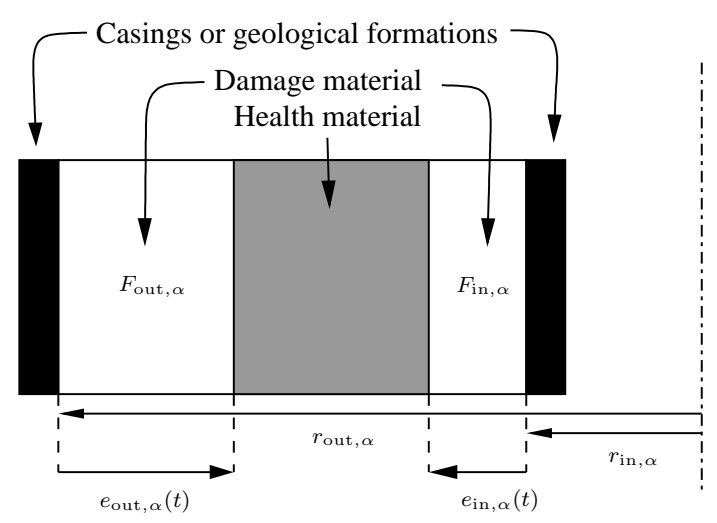

Fig. 3 Inner and outer degradation fronts

factor depends on domain $\Omega^{\alpha}$ and on the nature of the aggressive element (formation fluid or injected $\mathrm{CO}_{2}$ ) that causes the alteration.

\subsubsection{Stainless steel tubulars degradation}

For each domain $\Omega^{\alpha}$ made up of carbon steel material, two degradation mechanisms are modeled: the corrosion of casings by both pitting corrosion and general corrosion. These two mechanisms are modeled by the advance of four degradation fronts : the pitting corrosion fronts and the uniform corrosion fronts, for which $e_{\text {in }, \alpha}(t)=a_{\text {in }, \alpha} t$ and $e_{\text {out }, \alpha}(t)=a_{\text {out }, \alpha} t$. Behind the the pitting corrosion fronts and uniform corrosion fronts $e_{\mathrm{in}, \alpha}(t)$ and $e_{\mathrm{out}, \alpha}(t)$, the intrinsic permeability is multiplied respectively by the internal degradation factor $F_{\text {in }, \alpha}$ and by the external degradation factor $F_{\text {out }, \alpha}$ (see Fig. 3).

\subsubsection{Deterministic degradation model of the intrinsic permeability}

The model of damage intrinsic permeability of cement and steel materials is used as deterministic model. Each domain $\Omega^{\alpha}$ is defined (in cylindrical coordinates) as $\left[r_{\text {in }, \alpha}, r_{\text {out }, \alpha}\right] \times[0,2 \pi] \times\left[z_{\min , \alpha}, z_{\max , \alpha}\right]$. For each domain $\omega_{\alpha}, k_{\text {radial }, \alpha}(t)$ and $k_{\text {axial }, \alpha}(t)$ are the equivalent permeabilities of a system of three series permeabilities in the radial direction (for $k_{\text {radial }, \alpha}(t)$ ) and three parallel permeabilities in the axial direction and we have

$$
\begin{aligned}
& k_{\text {radial }, \alpha}(t)=k_{\text {radial }, \alpha}(0) b_{\text {radial }, \alpha}(t), \\
& k_{\text {axial }, \alpha}(t)=k_{\text {axial }, \alpha}(0) b_{\text {axial }, \alpha}(t),
\end{aligned}
$$

where

$$
\begin{aligned}
b_{\text {radial }, \alpha}(t) & =\left[\frac{e_{\mathrm{in}, \alpha}(t)}{F_{\mathrm{in}, \alpha}} \ln \left(\frac{r_{\mathrm{in}, \alpha}}{r_{\mathrm{in}, \alpha}+e_{\mathrm{in}, \alpha}(t)}\right)\right. \\
& +\left(r_{\mathrm{out}, \alpha}-r_{\mathrm{in}, \alpha}-e_{\mathrm{in}, \alpha}(t)-e_{\mathrm{out}, \alpha}(t)\right) \\
& \times \ln \left(\frac{r_{\mathrm{in}, \alpha}+e_{\mathrm{in}, \alpha}(t)}{r_{\mathrm{out}, \alpha}-e_{\mathrm{out}, \alpha}(t)}\right) \\
& \left.+\frac{e_{\mathrm{out}, \alpha}(t)}{F_{\mathrm{out}, \alpha}} \ln \left(\frac{r_{\mathrm{out}, \alpha}-e_{\mathrm{out}, \alpha}(t)}{r_{\mathrm{out}, \alpha}}\right)\right]^{-1} \\
& \times\left[\left(r_{\mathrm{out}, \alpha}-r_{\mathrm{in}, \alpha}\right) \ln \left(\frac{r_{\mathrm{in}, \alpha}}{r_{\mathrm{out}, \alpha}}\right)\right] \\
b_{\mathrm{axial}, \alpha}(t) & =\left[r_{\mathrm{out}, \alpha}^{2}-r_{\mathrm{in}, \alpha}^{2}\right]^{-1} \\
& \times\left[F_{\mathrm{in}, \alpha} e_{\mathrm{in}, \alpha}(t)\left(2 r_{\mathrm{in}, \alpha}+e_{\mathrm{in}, \alpha}(t)\right)\right. \\
& +F_{\text {out }, \alpha} e_{\mathrm{out}, \alpha}(t)\left(2 r_{\mathrm{out}, \alpha}-e_{\mathrm{out}, \alpha}(t)\right) \\
& +\left(r_{\mathrm{out}, \alpha}-e_{\mathrm{out}, \alpha}(t)\right)^{2} \\
& \left.-\left(r_{\mathrm{in}, \alpha}+e_{\mathrm{in}, \alpha}(t)\right)^{2}\right]
\end{aligned}
$$

From previous sections, for cement, we have $e_{\text {out }, \alpha}(t)=$ $a_{\text {out }, \alpha} \sqrt{t}$ and $e_{\text {in, } \alpha}(t)=a_{\text {in }, \alpha} \sqrt{t}$ while for casing, we have $e_{\mathrm{out}, \alpha}(t)=a_{\mathrm{out}, \alpha} t$ and $e_{\mathrm{in}, \alpha}(t)=a_{\mathrm{in}, \alpha} t$. Let's introduce vector $\underline{\mathbf{y}}_{\alpha}^{1}=\left(a_{\text {out }, \alpha}, a_{\text {in }, \alpha}, F_{\text {out }, \alpha}, F_{\text {in }, \alpha}\right)$ and vector $\underline{\mathbf{y}}_{\alpha}^{2}=\left(k_{\text {radial }, \alpha}(0), k_{\text {axial }, \alpha}(0)\right)$. The two functions $b_{\text {radial }, \alpha}(t)$ and $b_{\text {axial }, \alpha}(t)$ are rewritten as $b_{\text {radial }, \alpha}\left(t, \underline{\mathbf{y}}_{\alpha}^{1}\right)$ and $b_{\text {axial, } \alpha}\left(t, \underline{\mathbf{y}}_{\alpha}^{1}\right)$. Consequently, the mean intrinsic permeability matrix $\left[\underline{K}_{\alpha}\right]$ is written, for the radial and axial directions of the cylindrical coordinates, taken into account the degradation models, as

$$
\begin{aligned}
{\left[\underline{K}_{\alpha}\left(t, \underline{\mathbf{y}}_{\alpha}^{1}, \underline{\mathbf{y}}_{\alpha}^{2}\right)\right] } & = \\
& {\left.\left[\mathscr{B}_{\alpha}\left(t, \underline{\mathbf{y}}_{\alpha}^{1}\right)\right]^{T}\left[K^{0}\left(\underline{\mathbf{y}}_{\alpha}^{2}\right)\right]\left[\mathscr{B}_{\alpha}\left(t, \underline{\mathbf{y}}_{\alpha}^{1}\right)\right)\right], }
\end{aligned}
$$

in which, for any $\underline{\mathbf{y}}^{1}=\left(\underline{y}_{1}^{1}, \underline{y}_{2}^{1}, \underline{y}_{3}^{1}, \underline{y}_{4}^{1}\right)$ and $\underline{\mathbf{y}}^{2}=\left(\underline{y}_{1}^{2}, \underline{y}_{2}^{2}\right)$, the matrices $\left[\mathscr{B}_{\alpha}\left(t, \underline{\mathbf{y}}^{1}\right)\right]$ and $\left[\bar{K}^{0}\left(\underline{\mathbf{y}}^{2}\right)\right]$ are diagonal $(2 \times$ 2) real matrices written as

$$
\left[\mathscr{B}_{\alpha}\left(t, \underline{\mathbf{y}}^{1}\right)\right]=\left(\begin{array}{cc}
\sqrt{b_{\text {radial }, \alpha}\left(t, \underline{\mathbf{y}}^{1}\right)} & 0 \\
0 & \sqrt{b_{\text {axial }, \alpha}\left(t, \underline{\mathbf{y}}^{1}\right)}
\end{array}\right)
$$

$\left[K^{0}\left(\underline{\mathbf{y}}^{2}\right)\right]=\left(\begin{array}{cc}\underline{y}_{1}^{2} & 0 \\ 0 & \underline{y}_{2}^{2}\end{array}\right)$

\section{Mean computational model and sources of uncertainties}

In this section, a synthetic equation representing the computational model is introduced and then, the different sources of uncertainties are listed. 


\subsection{Mean computational model}

The spatial discretization of the nonlinear boundary value problem described in Section 2 yields the mean computational model which is synthetically written as

$\underline{A}\left(\underline{\mathbf{u}}(t) ; t, \underline{\mathbf{y}}_{1}^{1}, \ldots, \underline{\mathbf{y}}_{n}^{1}, \underline{\mathbf{y}}_{1}^{2}, \ldots, \underline{\mathbf{y}}_{n}^{2}, \underline{\mathbf{y}}_{1}^{3}, \ldots, \underline{\mathbf{y}}_{n}^{3}\right)=0$,

where, for $\alpha=1, \ldots, n$, vectors $\underline{\mathbf{y}}_{\alpha}^{1}$ and $\underline{\mathbf{y}}_{\alpha}^{2}$ have been defined in the previous Section 2.3 .3 and where vectors $\underline{\mathbf{y}}_{\alpha}^{3}=\left(p_{e c, \alpha}, s_{r, \alpha}^{\mathrm{w}}, \eta_{\alpha}\right)$ (see Section 2.1) have been introduced. In Eq. 18, $\underline{\mathbf{u}}(t)$ is the deterministic state vector of the coupled system at time $t$. Below, we consider an observation vector $\underline{\mathbf{w}}(t)$ for $t>0$ deduced from $\{\underline{\mathbf{u}}(t), t>0\}$. At time $t$, the mean computational model depends on the mean intrinsic permeability ma$\operatorname{trix}\left[\underline{K}_{\alpha}\left(t, \underline{\mathbf{y}}_{\alpha}^{1}, \underline{\mathbf{y}}_{\alpha}^{2}\right)\right]$ and on parameters $\mathbf{y}_{\alpha}^{3}$.

\subsection{Sources of uncertainties in the mean computational model}

In such a computational model, the main sources of uncertainties are the following. There are uncertain system parameters which are $\underline{\mathbf{y}}_{\alpha}^{1}, \underline{\mathbf{y}}_{\alpha}^{2}$ and $\underline{\mathbf{y}}_{\alpha}^{2}$. In addition there are model uncertainties induced by modeling errors related to the choice of the evolution law of the mean instrinsic permeability matrix $\left[\underline{K}_{\alpha}\left(t, \underline{\mathbf{y}}_{\alpha}^{1}, \underline{\mathbf{y}}_{\alpha}^{2}\right)\right]$.

\section{Methodology used for uncertainty quantification}

In this section, the main concepts concerning uncertainty quantification are summarized and the methodology used in Sections 5 and 6 to construct the probabilistic modeling of both the system-parameter uncertainties and the model uncertainties induced by the modeling errors, is presented.

Types of approach for stochastic modeling of uncertainties. The parametric probabilistic approach of system-parameter uncertainties consists in modeling the uncertain parameters of the computational model by random variables and then in constructing prior probability distributions of these random variables using the available information. The nonparametric probabilistic approach of model uncertainties induced by modeling errors, which has been proposed in [33], is a method which allows a prior probability model of model uncertainties to be taken into account at the operators level by introducing random operators and not at the model output level by introducing an additive noise (which could not been identified for a prior probability model for which no experimental data are available). The nonparametric probabilistic approach is based on the use of the random matrix theory [24]. It consists in directly constructing the stochastic modeling of the operators of the mean computational model. In Sections 5 and 6 , the parametric probabilistic approach of system-parameter uncertainties is coupled with the nonparametric probabilistic approach of model uncertainties induced by modeling errors $[6,37,38]$.

Methodology for constructing the prior probability model of uncertainties. The Maximum Entropy (MaxEnt) principle (that is to say the maximization of the level of uncertainties) which has been introduced by [17] in the context of Information Theory [30], is a powerful tool which allows the prior probability distribution of a random variable to be constructed under the constraints defined by the available information. Concerning the methodology that we use in Sections 5 and 6 for constructing (1) the probability distribution of a random vector, we refer the reader, for instance, to [22] for low-stochastic dimension and to [35] for high-stochastic dimension, and (2) the probability distribution of random matrices with values in the set of all the positivedefinite symmetric real matrices, we refer the reader to $[33,34,37]$. Many developments and applications have been performes withthis type of approaches $[2,6,11,2$, $3,36]$

Propagation of uncertainties and stochastic solver. Two classes of methodologies yielding two types of stochastic solvers can be developed: the spectral stochastic methods [14], the sampling techniques such as the direct Monte Carlo numerical simulation method (see for instance $[4,19,26,29,27])$. In the present paper, we will construct generators of independent realizations for the random vectors and the random matrices corresponding to the prior probability distributions that we will construct in Sections 5 and 6, and, in Section 7, we will use the Monte Carlo simulation method and the mathematical statistics to analyze the propagation of uncertainties in the computational model.

Identification of the prior and posterior probability models of uncertainties. The identification of the parameters of the probability model of uncertainties (parametric and nonparametric probabilistic approaches) is a problem belonging to the class of the statistical inverse problems (see for instance $[18,41]$ ). When experimental data are not available, then, only a family of prior probability models of uncertainties can be constructed as explained above and therefore, the unknown parameters which are used in the prior probabil- 
ity distributions, must be used to carry out a sensitivity analysis. Such an approach allows a robust analysis to be performed with respect to the level of uncertainties. This is the situation which is considered in the present paper.

\section{Probabilistic modeling of uncertainties related to the mean computational model}

In this section, the uncertainties are taken into account by using the generalized probabilistic approach $[37,38]$ consisting in simultaneously using the parametric probabilistic approach for the uncertain model parameters and the nonparametric probabilistic approach for model uncertainties induced by modeling errors $[33,34]$.

For the sake of brevity, the subscript $\alpha$ are dropped in vectors $\underline{\mathbf{y}}_{\alpha}^{1}, \underline{\mathbf{y}}_{\alpha}^{2}$ and $\underline{\mathbf{y}}_{\alpha}^{3}$, in components $\underline{y}_{\alpha, 1}^{1}, \underline{y}_{\alpha, 2}^{1}$ and in matrix $\left[\underline{K}_{\alpha}\right]$. Therefore, Eq. (15) is rewritten as

$\left[\underline{K}\left(t, \underline{\mathbf{y}}^{1}, \underline{\mathbf{y}}^{2}\right)\right]=\left[\mathscr{B}\left(t, \underline{\mathbf{y}}^{1}\right)\right]^{T}\left[K^{0}\left(\underline{\mathbf{y}}^{2}\right)\right]\left[\mathscr{B}\left(t, \underline{\mathbf{y}}^{1}\right)\right]$.

\subsection{Parametric probabilistic approach of} system-parameter uncertainties

All the random quantities are defined on a probability space denoted by $(\Theta, \mathcal{T}, \mathcal{P})$. The vector $\mathbf{y}^{1}$ is modeled by a random vector $\mathbf{Y}^{1}=\left(Y_{1}^{1}, Y_{2}^{1}, Y_{3}^{1}, \bar{Y}_{4}^{1}\right)$. The vector $\underline{\mathbf{y}}^{2}$ is modeled by a random vector $\mathbf{Y}^{2}=\left(Y_{1}^{2}, Y_{2}^{2}\right)$ with values in $\mathbb{R}^{2}$ and the vector $\mathbf{y}^{3}$ is modeled by a random vector $\mathbf{Y}^{3}=\left(Y_{1}^{3}, Y_{2}^{3}, Y_{3}^{3}\right)^{-}$with values in $\mathbb{R}^{3}$. For the construction of the probability distributions of these random vectors, there is no available information concerning the statistical dependencies between $\mathbf{Y}^{1}, \mathbf{Y}^{2}$ and $\mathbf{Y}^{3}$. Consequently, the use of the MaxEnt principle $[17,22]$ implies that all the random variables $Y_{1}^{1}, Y_{2}^{1}$, $Y_{3}^{1}, Y_{4}^{1}, Y_{1}^{2}, Y_{2}^{2}, Y_{1}^{3}, Y_{2}^{3}, Y_{3}^{3}$ are statistically independent.

Concerning the uncertainties related to material parameters $p_{e c, \alpha}, s_{r, \alpha}^{\mathrm{W}}, \eta_{\alpha}$, the parametric probabilistic approach consists in replacing, in Eq. (18), the deterministic vectors $\underline{\mathbf{y}}_{1}^{3}, \ldots, \underline{\mathbf{y}}_{n}^{3}$ by random vectors $\mathbf{Y}_{1}^{3}, \ldots, \mathbf{Y}_{n}^{3}$.

5.2 Nonparametric probabilistic approach of modeling errors induced by the statistical dependencies

Since the random variables $Y_{1}^{2}$ and $Y_{2}^{2}$ are constructed as statistically independent random variables (because there is no available information on their statistical dependencies), a modeling error is introduced and taken into account by the nonparametric probabilistic approach $[33,34]$ which involves a random matrix $\left[\mathbf{G}^{0}\right]$ with values in the set $M_{2}^{+}(\mathbb{R})$ of all the $(2 \times 2)$ definite-positive real matrices. Random matrix $\left[\mathbf{G}^{0}\right]$ and random vectors $\mathbf{Y}^{1}$, $\mathbf{Y}^{2}$ and $\mathbf{Y}^{3}$ are statistically independent. Under these conditions, the nonparametric probabilistic approach used in the framework of the generalized probabilistic approach of uncertainties [37] consists in replacing random matrix $\left[\mathbf{K}^{0}\right]$ by the random matrix $\left[\mathbb{K}^{0}\right]$ defined as

$$
\left[\mathbb{K}^{0}\right]=\left[\mathcal{L}^{0}\left(\mathbf{Y}^{2}\right)\right]^{T}\left[\mathbf{G}^{0}\right]\left[\mathcal{L}^{0}\left(\mathbf{Y}^{2}\right)\right]
$$

In this equation, $\left[\mathcal{L}^{0}\left(\mathbf{Y}^{2}\right)\right]=\left[K^{0}\left(\mathbf{Y}^{2}\right)\right]^{1 / 2}$ is a diagonal matrix. The probabilistic model of the intrinsic permeability matrices, related to the uncertainties on parameters $\underline{\mathbf{y}}^{1}$ and $\underline{\mathbf{y}}^{2}$ is constructed by replacing in Eq. (19), deterministic vector $\underline{\mathbf{y}}^{1}$ by random vector $\mathbf{Y}^{1}$ and, matrix $\left[K^{0}\left(\mathbf{y}^{2}\right)\right]$ by random matrix $\left[\mathbb{K}^{0}\right]$, defined by Eq. (20). The deterministic matrix $\left[\underline{K}\left(t, \mathbf{y}^{1}, \mathbf{y}^{2}\right)\right]$ are then replaced by the random matrix $[\mathbf{K}(t)]$ defined by

$$
\begin{aligned}
& {[\mathbf{K}(t)]=} \\
& \quad\left[\mathcal{B}\left(t, \mathbf{Y}^{1}\right)\right]^{T}\left[\mathcal{L}^{0}\left(\mathbf{Y}^{2}\right)\right]^{T}\left[\mathbf{G}^{0}\right]\left[\mathcal{L}^{0}\left(\mathbf{Y}^{2}\right)\right]\left[\mathcal{B}\left(t, \mathbf{Y}^{1}\right)\right] .
\end{aligned}
$$

5.3 Nonparametric probabilistic approach of modeling errors induced by the evolution law of the intrinsic permeability matrices

The modeling errors on the evolution law of the intrinsic permeability matrix $\left[\underline{K}\left(t, \mathbf{y}^{1}, \mathbf{y}^{2}\right)\right]$ induces model uncertainties that are also considered in the context of the generalized probabilistic approach. We therefore introduce the random matrix $[\mathbf{G}]$ with values in $\mathbf{M}_{2}^{+}(\mathbb{R})$. Consequently, the random matrix $[\mathbf{K}(t)]$ is replaced by the random matrix $[\mathbb{K}(t)]$ defined by

$$
[\mathbb{K}(t)]=[\mathbf{L}(t)]^{T}[\mathbf{G}][\mathbf{L}(t)] .
$$

In these equations, the matrix $[\mathbf{L}(t)]$ and $[\mathbf{L}(t)]$ are such that

$$
[\mathbf{L}(t)]=\left[\mathbf{L}^{0}\right]\left[\mathcal{L}^{0}\left(\mathbf{Y}^{2}\right)\right]\left[\mathcal{B}\left(t, \mathbf{Y}^{1}\right)\right]
$$

in which the random matrix $\left[\mathbf{L}^{0}\right]$ corresponds to the Cholesky factorization $\left[\mathbf{G}^{0}\right]=\left[\mathbf{L}^{0}\right]^{T}\left[\mathbf{L}^{0}\right]$ of the random matrix $\left[\mathbf{G}^{0}\right]$. Since there is no available information on the statistical dependencies of the random variables introduced above, the MaxEnt principle then implies that $\mathbf{Y}^{1}, \mathbf{Y}^{2}, \mathbf{Y}^{3},\left[\mathbf{G}^{0}\right],\left[\mathbf{G}^{0}\right]$ and $[\mathbf{G}]$ are statistically independent. 


\subsection{Stochastic computational model}

Finally, the mean computational model (without uncertainties) defined by Eq. (18) is replaced by a stochastic computational model (due to the probability modeling of uncertainties) for which the random state vector $\mathbf{U}(t)$ at time $t$ depends (1) on random vector $\mathbf{Y}^{1}$ and $\mathbf{Y}^{3}$ related to the uncertain system parameters, (2) on random initial condition vector $\mathbf{Y}^{2},(3)$ on the random matrix $[\mathbf{G}]$ that describes model uncertainties associated with the intrinsic permeability matrices at time $t$ and (4) on the random matrix $\left[\mathbf{G}^{0}\right]$ which describes model uncertainties associated with the initial conditions of both phases.

\section{Construction of the prior probability distributions and their associated generators for random variables and for random matrices involved in the probabilistic modeling of uncertainties}

In this section, we briefly present the methodology followed for constructing the prior probability distributions. Then, the effective construction is developed for the random matrices and then for the random variables.

6.1 Methodology for constructing the prior probability distributions

Given the probabilistic modeling introduced in the Section 5 and taken into account the independence of the introduced random variables, the prior probability distribution of each random variable $Y_{1}^{1}, Y_{2}^{1}, Y_{3}^{1}, Y_{4}^{1}, Y_{1}^{2}$, $Y_{2}^{2}, Y_{1}^{3}, Y_{2}^{3}, Y_{3}^{3}$ or each random matrix $\left[\mathbf{G}^{0}\right]$ or $[\mathbf{G}]$ must be constructed. It is assumed that each prior probability distribution is represented by the probability density function $p_{Y_{1}^{1}}, p_{Y_{2}^{1}}, p_{Y_{3}^{1}}, p_{Y_{4}^{1}}, p_{Y_{1}^{2}}, p_{Y_{2}^{2}}, p_{Y_{1}^{3}}, p_{Y_{2}^{3}}, p_{Y_{3}^{3}}$, $p_{\left[\mathbf{G}^{0}\right]}$ or $p_{[\mathbf{G}]}$. The construction of each prior probability density function is carried out using the MaxEnt principle under the constraints defined by the available information. It is therefore necessary to define the available information for each random variable, which is the same for each random matrix $\left[\mathbf{G}^{0}\right]$ or $[\mathbf{G}]$, and for each random variable $Y_{1}^{1}, Y_{2}^{1}, Y_{3}^{1}, Y_{4}^{1}, Y_{1}^{2}, Y_{2}^{2}, Y_{1}^{3}, Y_{2}^{3}, Y_{3}^{3}$.

6.2 Effective construction of the prior probability distributions and their associated generators for the random matrices

Since the probabilistic model for the modeling uncertainties is constructed with a nonparametric probabilis- tic approach, and since these matrices are positive-definite, then $\left[\mathbf{G}^{0}\right]$ and $[\mathbf{G}]$ must belong to the ensemble of the random matrices $\mathrm{SG}^{+}$introduced in [34]. For the sake of brevity, we introduce the generic random matrix $[\mathbb{G}]$, defined on $(\Theta, \mathcal{T}, \mathcal{P})$, with values in $\mathbb{M}_{2}^{+}(\mathbb{R})$, belonging to $\mathrm{SG}^{+}$, with the prior probability distribution $P_{[\mathbb{G}]}(\widetilde{d} G)=p_{[\mathbb{G}]}([G]) \widetilde{d} G$, representing any one of the random matrices $\left[\mathbf{G}^{0}\right]$ or $[\mathbf{G}]$. The volume element on the space of all the symmetric $(2 \times 2)$ real matrices is written as $\widetilde{d} G=\sqrt{2} d[G]_{11} d[G]_{12} d[G]_{22}$ and the prior probability density function with respect to $\widetilde{d} G$ are such (see [33]) that,

$$
\begin{aligned}
p_{[\mathbb{G}]}([G])=\mathbb{1}_{\mathbb{M}_{2}^{+}(\mathbb{R})}([G]) & \times C_{\mathbb{G}} \times(\operatorname{det}[G])^{3\left(1-\delta_{G}^{2}\right)\left(2 \delta_{G}^{2}\right)^{-1}} \\
& \times \exp \left\{-3\left(2 \delta_{G}^{2}\right)^{-1} \operatorname{tr}[G]\right\}
\end{aligned}
$$

where $\operatorname{tr}[G]$ and $\operatorname{det}[G]$ are the trace and the determinant of the matrix $[G]$. The parameter $\delta_{\mathbb{G}}$ is a dispersion coefficient which allows the level of statistical fluctuations (that is to say the level of uncertainties) of random matrix $[\mathbb{G}]$ to be controlled. The dispersion parameter must be such that $0<\delta_{\mathbb{G}}<(3 / 7)^{1 / 2}$. The positive constant $C_{\mathbb{G}}$ is written as

$C_{\mathbb{G}}=\frac{(2 \pi)^{-1 / 2}\left(\frac{3}{2 \delta_{\mathbb{G}}^{2}}\right)^{3\left(\delta_{\mathbb{G}}^{2}\right)^{-1}}}{\Gamma\left(\frac{3}{2 \delta_{\mathbb{G}}^{2}}\right) \Gamma\left(\frac{3}{2 \delta_{\mathbb{G}}^{2}}-\frac{1}{2}\right)}$,

where $\Gamma$ is the gamma function such that, for $z>0$, $\Gamma(z)=\int_{0}^{+\infty} t^{z-1} e^{-t} d t$. The generator of independent realizations of random matrix $[\mathbb{G}]$, for which the prior probability density function is defined by Eq. (24), can easily be constructed using the following algebraic representation of $[\mathbb{G}]$,

$[\mathbb{G}]=\left[\mathbf{L}_{\mathbb{G}}\right]^{T}\left[\mathbf{L}_{\mathbb{G}}\right]$

where $\left[\mathbf{L}_{\mathbb{G}}\right]$ is a random upper triangular matrix with values in $M_{2}(\mathbb{R})$ such that $\left[\mathbf{L}_{\mathbb{G}}\right]_{11}=\sigma \sqrt{2 V_{1}},\left[\mathbf{L}_{\mathbb{G}}\right]_{22}=$ $\sigma \sqrt{2 V_{2}},\left[\mathbf{L}_{\mathbb{G}}\right]_{12}=\sigma U_{12}$ in which $\sigma=\delta_{\mathbb{G}} / \sqrt{3}$ and where $\left\{V_{1}, V_{2}, U_{12}\right\}$ are independent random variables such that $U_{12}$ is a normalized gaussian random variable and, for $j=1,2, V_{j}$ is a Gamma random variable for which the probability density function is $p_{V_{j}}(v)=\mathbb{1}_{\mathbb{R}^{+}}(v)$ $\Gamma\left(z_{j}\right)^{-1} v^{z_{j}-1} e^{-v}$ with $z_{j}=3 /\left(2 \delta_{\mathbb{G}}^{2}\right)+(1-j) / 2$.

It should be noted that parameter $\delta_{\mathbb{G}}$ allows the level of model uncertainties induced by modeling errors to be controlled for the prior probability model. If no experimental data are available, then a family of prior probability models is spanned when $\delta_{\mathbb{G}}$ runs through its admissible set. This family then allows a sensitivity analysis to be carried out with respect to the level of uncertainties which is unknown and consequently, allows 
a robust analysis with respect to model uncertainties to be performed. If experimental data are available for given output observation of the system, then an optimal value of parameter $\delta_{\mathscr{G}}$ can be estimated using the maximum likelihood method [28,39] and experimental data as explained and validated in $[34,37,38]$.

6.3 Effective construction of the prior probability distributions and their associated generators for the random variables

Let $Q$ be the real-valued random variable defined on $(\Theta, \mathcal{T}, \mathcal{P})$ with probability distribution $P_{Q}(d q)=p_{Q}(q)$ $d q$. Random variable $Q$ represents any one of the random variables $Y_{1}^{1}, Y_{2}^{1}, Y_{3}^{1}, Y_{4}^{1}, Y_{1}^{2}, Y_{2}^{2}, Y_{1}^{3}, Y_{2}^{3}$ or $Y_{3}^{3}$. We then define the available information for $Q$ and the prior probability density function $p_{Q}$ is constructed using the MaxEnt principle. For random variable $Q$, the available information are the following. The support of $p_{Q}$ is the set $\left[q_{\min }, q_{\max }\right]$. The function $q \mapsto p_{Q}(q)$ must go to zero when $q \longrightarrow q_{\min }$ and $q \longrightarrow q_{\max }$. Since there is no additional information concerning the behavior of $p_{Q}$ in the neighborhood $q_{\min }$ and $q_{\max }$, we will then assume that $E\left\{\log \left(Q-q_{\text {min }}\right)\right\}<+\infty$ and $E\left\{\log \left(q_{\max }-Q\right)\right\}<+\infty$, in which $E$ denotes the mathematical expectation. The MaxEnt principle then yields

$p_{Q}(q)=c_{0} \mathbb{1}_{\left[q_{\min }, q_{\max }\right]}(q)\left(q-q_{\min }\right)^{\lambda}\left(q_{\max }-q\right)^{\mu}$,

in which $\lambda$ and $\mu$ are two deterministic positive constants and where $c_{0}$ is the constant of normalization. Since parameters $\lambda$ and $\mu$ have no physical meaning, these parameters are replaced by the mean value $m_{Q}=$ $E\{Q\}$ and by the standard deviation $\sigma_{Q}$ of random variable $Q$. It can easily be shown that random variable $Q$ can be written as

$Q=\left(q_{\max }-q_{\min }\right) Z+q_{\min }$,

in which $Z$ is a Beta random variable with values in $[0,1]$ for which the probability density function is written as $p_{Z}(z)=\mathbb{1}_{[0,1]}(z) B(a, b)^{-1} z^{a-1}(1-z)^{b-1}$ with $B(a, b)=\Gamma(a) \Gamma(b) / \Gamma(a+b)$. The parameters $a$ and $b$ are defined by

$a=\frac{m_{Z}^{2}}{\sigma_{Z}^{2}}\left(1-m_{Z}\right)-m_{Z}$,

$b=\left(1-m_{Z}\right)\left\{\frac{m_{Z}\left(1-m_{Z}\right)}{\sigma_{Z}^{2}}-1\right\}$,

in which the mean value $m_{Z}$ and the variance $\sigma_{Z}^{2}$ of random variable $Z$ are written as $m_{Z}=\left(m_{Q}-q_{\min }\right) /\left(q_{\max }-\right.$ $\left.q_{\text {min }}\right)$ and $\sigma_{Z}=\sigma_{Q} /\left(q_{\max }-q_{\min }\right)$.

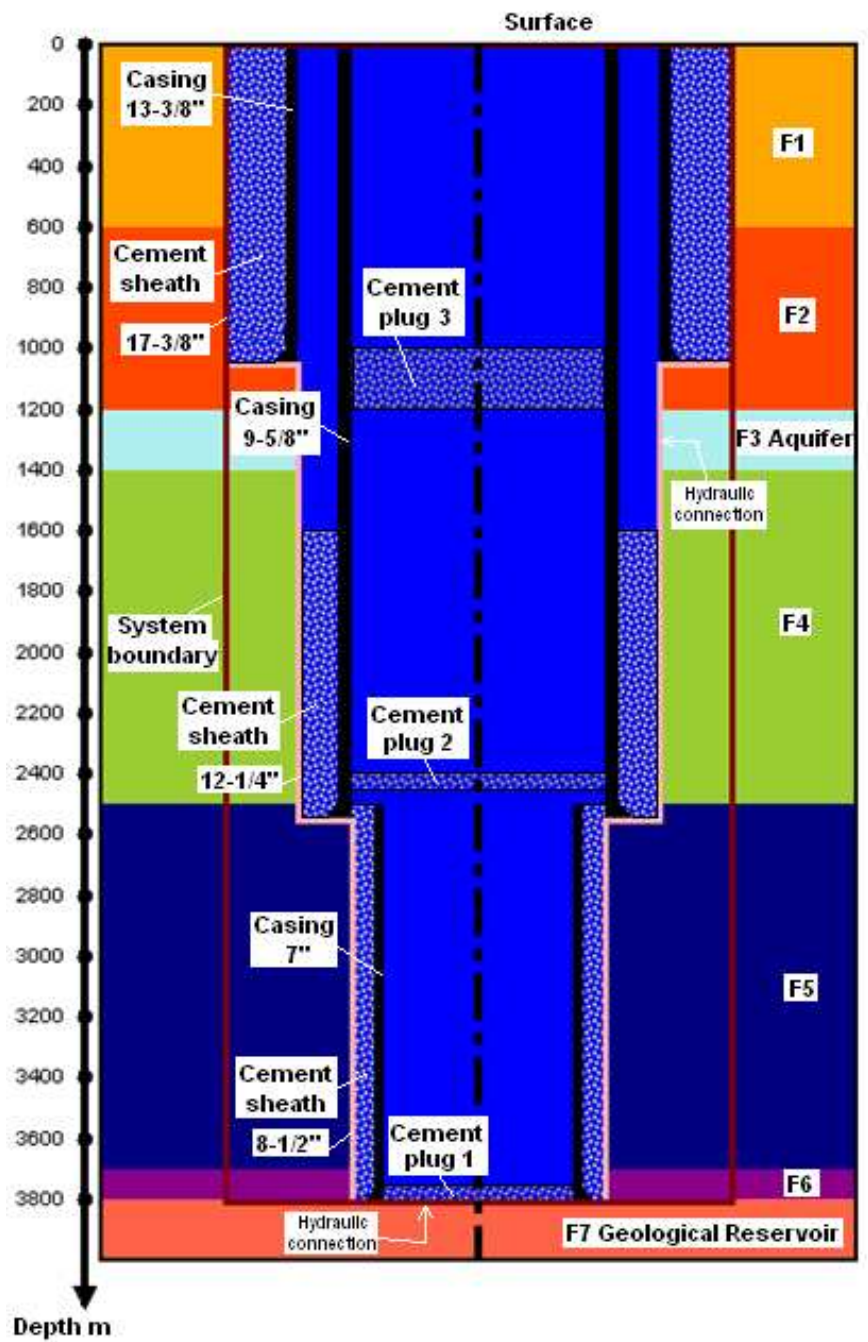

Fig. 4 Well and its elements (not at scale)

\section{Application}

The model and the methodology presented in the previous sections are used to analyzed the complex system shown in Fig. 4. This analysis consists in studying the well integrity assessment of a hypothetical abandoned well located in a geological storage site of $\mathrm{CO}_{2}$. This problem explores the $\mathrm{CO}_{2}$ flow within well from $\mathrm{CO}_{2}$ geological storage. The geological formations in contact with the well are (see Fig. 4) :

- Limestone layers (F1, F2, F4) with average permeability;

- A clay formation (F5) with very low permeability (caprock);

- A connected aquifer (F3) with high permeability;

- The reservoir (F6) in which CO2 is stored (very permeable layer) 
The cement sheaths are initially considered water-saturatedas uncertain parameters, they are modeled by random Moreover the presence of a connected aquifer ensures a water supply within the cement sheaths. Considering the pressure differential gradient between the $\mathrm{CO}_{2}$ reservoir and the upper well elements, and the cement sheaths permeability, $\mathrm{CO}_{2}$ gas can flow through the well. The initial and limit conditions assessed for the simulations are the following

- Reservoir water saturation is at the residual water saturation;

- All other elements are considered water-saturated;

- The aquifer is at hydrostatic pressure;

- The reservoir pressures (water and $\mathrm{CO}_{2}$ fluid) are time dependent.

The geological formation F7 is a deep saline aquifer which constitutes the geological reservoir of $\mathrm{CO}_{2}$. It is assumed that the period of injection is 30 years and that one million tons of $\mathrm{CO}_{2}$ is injected into the subsurface (formation F7) by year. The nonlinear computational model is constructed using the integrated finitedifference method. The discretized equations are then solved using the Newton-Raphson method

\subsection{Parameters and data of the model}

The well and its near geologic environment are described in Section 2 by their geometric and material characteristics. The initial conditions, the boundary conditions, the fluid characteristics and the physical parameters are given in Table 1 of the Appendix. For this application, a preliminary study (not presented in this paper) has allowed the highest uncertain parameters to be identified which are the cement quality (for sheaths and plugs) and the physical parameters of the geologic environment near the well. These parameters are then modeled by random variables, as explained in Sections 5 and 6 , when probabilistic model is considered (Section 7.2.2). The values of the parameters of the probability distributions of the uncertain parameters of the mechanical system are summarized in Table 2 of the Appendix.

\subsection{Results and discussions}

We are interested in the quantity of migrating $\mathrm{CO}_{2}$ for several elements of the physical system (e.g. aquifer and surface) and at a given time. The outputs of interest are deterministic variables if the input parameters are fixed to their nominal values (the most likely values) . In such a case, only one simulation is performed with the mean computational model (Eq. 18). When the input parameters (the system parameters) are considered variables and several simulations are performed in the context of the use of the Monte Carlo simulation as the stochastic solver of the stochastic computational model.

\subsubsection{Mean computational model}

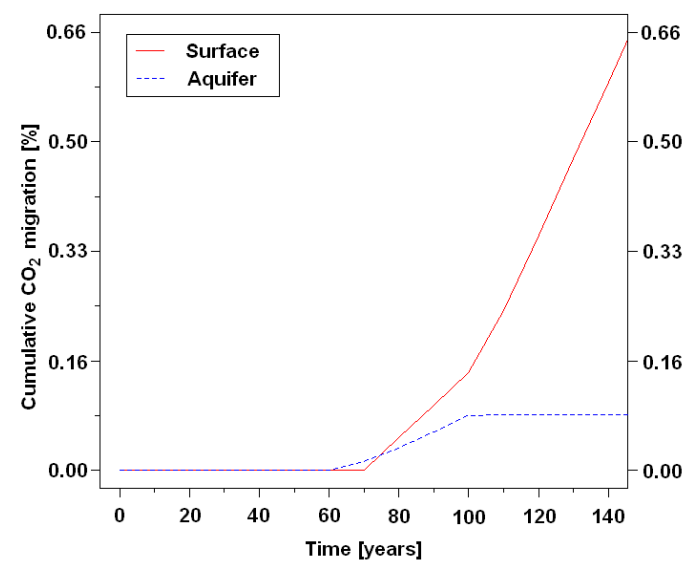

Fig. 5 Cumulative migration mass of $\mathrm{CO}_{2}$ for the mean (or nominal) computational model

The mean (or nominal) model is assumed to be the mean computational model and it is used to assess the cumulative mass of $\mathrm{CO}_{2}$ migration along the well from the $\mathrm{CO}_{2}$ reservoir. The results are presented in Fig. 5 and they are expressed as a percentage of the total amount injected. The temporal evolution of leakage of $\mathrm{CO}_{2}$ can be divided in three intervals. The first interval, between 0 and 60 years, shows the penetration of $\mathrm{CO}_{2}$ through the first plug of the well and the cement sheaths in the lower inner section of the well. The second interval, between 60 and 100 years, corresponds to the beginning of a simultaneous $\mathrm{CO}_{2}$ migration into the aquifer and to the surface. In the third interval, between 100 and 140 years, $\mathrm{CO}_{2}$ migration is more important in surface than into the aquifer where quantities remain stable.

Figure 6 displays five snapshots which show the cement water saturation at different times: 0, 30, 50, 60 and 80 years. This allows the paths of $\mathrm{CO}_{2}$ migration along the well to be identified. These paths can be explained as follows. At $t=30$ years, $\mathrm{CO}_{2}$ has risen about $80 \%$ of the height of the first horizontal cement barrier (plug 1) in the lower inner section of the well. The corrosive action of the fluid in the aquifer (formation F3) has begun to affect the permeability of the steel casing. At $t=50$ years, the $\mathrm{CO}_{2}$ is constituted of gas bubbles that rise quickly in the interior of the water which 

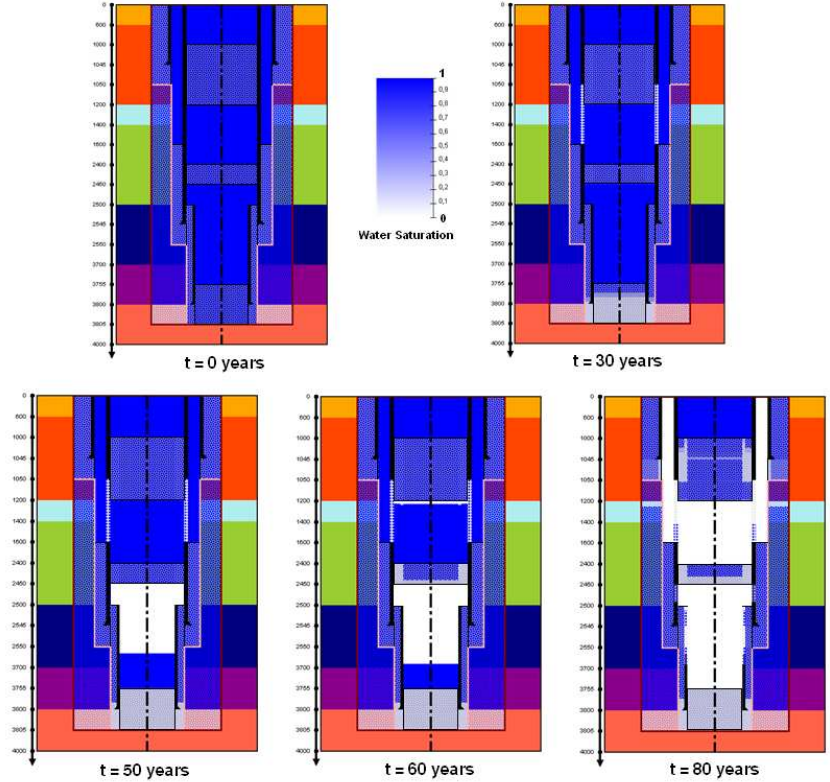

Fig. 6 Snapshot of the cement water saturation at time 0, $30,50,60$ and 80 years

fills the well. These gas bubbles begin to degrade the second horizontal cement barrier (plug 2). At $t=60$ years, $\mathrm{CO}_{2}$ has mainly crossed at the endpoints of the second horizontal cement barrier, has begun to rise in the interior of the well, and degrades the underpart of the third horizontal cement barrier (plug 3). At $t=80$ years, the steel casing in the aquifer is highly degraded and allows the flow of $\mathrm{CO}_{2}$ and its ascent into the space limited by the two out steel casings. An amount of $\mathrm{CO}_{2}$ has already migrated into the aquifer and in surface.

In order to take into account the most of possibilities of migration of $\mathrm{CO}_{2}$ from the reservoir linked to the well integrity, we present an analysis in which, both the system-parameter uncertainties and the modeling errors are taken into account in the mean computational model by using the generalized probabilistic approach introduced in Sections 5 and 6.

\subsubsection{Probabilistic model of uncertainties}

The stochastic computational model presented in Sections 5 and 6 is used for which the input probabilistic parameters are defined in Table 2 in Appendix The prediction of the cumulative mass of $\mathrm{CO}_{2}$ migration from the reservoir along the well is assessed. The $\mathrm{CO}_{2}$ migrations in surface and into the aquifer are presented in Figs. 7 and 8 for both approaches: the parametric probabilistic approach for the uncertain system parameters (PPAU) and generalized (or nonparametric) probabilistic approach for the model uncertainties in- duced by modeling errors (GPAU). For matrices $\left[\mathbf{G}^{0}\right]$ and $[\mathbf{G}]$, an unique value of parameter $\delta_{\mathbb{G}}$ is used and equal to 0.10 . The results obtained with the mean computational model are also presented in the same figures (so called the nominal model results). Figure 7 shows

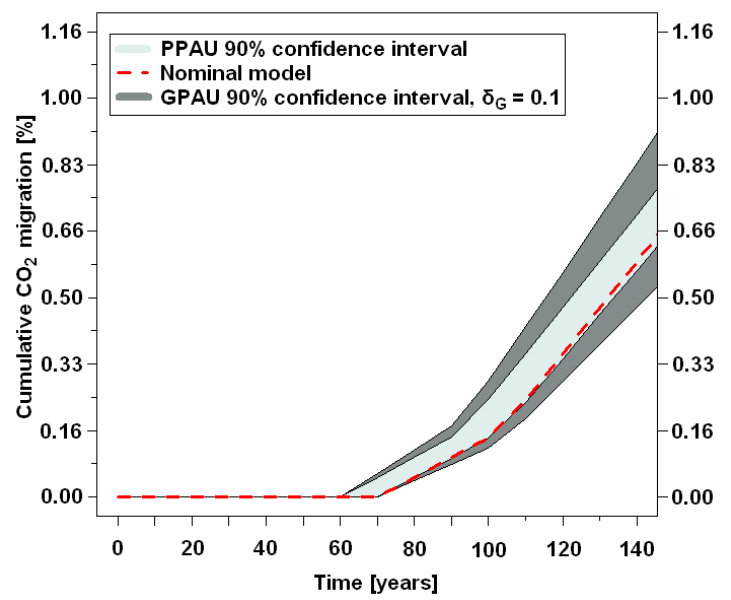

Fig. 7 Confidence region with a probability level $90 \%$ of the cumulative $\mathrm{CO}_{2}$ migration in surface

that the values calculated at the surface with the mean computational model are included in the confidence interval of PPAU, particularly on the lower quantile (5\%). Concerning the calculated values with the mean computational model in the aquifer, Fig. 8 shows that they are included in the confidence interval of PPAU, near the upper quantile (95\%). Starting from $t=100$ years, the amount of $\mathrm{CO}_{2}$ mass released into the aquifer remains stable because the leak of $\mathrm{CO}_{2}$ occurs mainly in surface. The confidence regions calculated with GPAU, in surface and into the aquifer, are higher than those obtained with PPAU. It should be noted that with the probabilistic approach, it can be seen that $\mathrm{CO}_{2}$ leakage from the reservoir in the surface and into the aquifer is a random event that has a non zero probability of occurrence at a time earlier than what the mean computational model predicts: in the surface starting from $t=60$ years (starting from $t=70$ years for the mean computational model) and into the aquifer starting from $t=50$ years (starting from $t=60$ for the mean computational model). For $t=140$ years, Fig. 9 shows the convergence of the mean value and of the quantile values $(5 \%$ and $95 \%$ ) of the cumulative mass of $\mathrm{CO}_{2}$ migration in surface predicted with the two probabilistic approaches, as a function of the number $N$ of simulations. The convergence of the mean value for the two probabilistic approaches is reached for $N>400$ simulations, while the convergence of quantile values is 


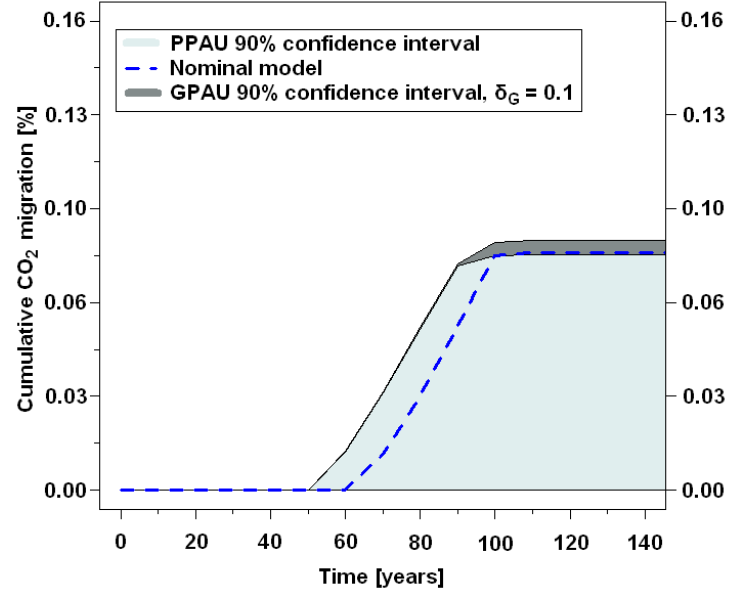

Fig. 8 Confidence region with a probability level $90 \%$ of cumulative $\mathrm{CO}_{2}$ migration in aquifer

reached for $N>2000$.

The probability $P_{f}$ of exceeding a critical threshold $w_{c}=0.03 \%$ of the total injected quantity during a period of 30 years with 1 million tons injected by year, is shown in Fig. 10 as a function of time, for the two probabilistic approaches. Figure 10 shows that GPAU is able to detect a low probability of exceeding the critical level at initial phase of $\mathrm{CO}_{2}$ migration at the surface. This is because the confidence regions predicted with the GPAU is more important than with the PPAU. Starting from $t=80$ years, we can also observe the probability of exceeding the threshold reaching a certain range, i.e. where $P_{f}=1$, for the two probabilistic approaches. In summary, the fact to take into account model uncertainties will increase the width of the confidence regions. It should be noted that the confidence regions given by the PPAU are included in the confidence regions given by the GPAU. In addition, it is convenient to perform a sensitivity analysis of the statistical dispersion parameter $\delta_{\mathbb{G}}$ (same values for matrices $\left[\mathbf{G}^{0}\right]$ and $[\mathbf{G}]$ ) to assess the degree of robustness of the stochastic computational model, i.e. the sensitivity of model output values with respect to $\delta_{\mathbb{G}}$.

\subsubsection{Sensitivity analysis of model output values with respect to $\delta_{\mathbb{G}}$}

As explained at the end of Section 6.2, since no experimental data are available for output observations of the system, an optimal value of the dispersion parameter $\delta_{\mathscr{G}}$ (same and unique value for $\left[\mathbf{G}^{0}\right]$ and $[\mathbf{G}]$ ) which controls the level of model uncertainties cannot be estimated. Consequently, only a robust analysis can be performed with respect to this parameter, that is to say,

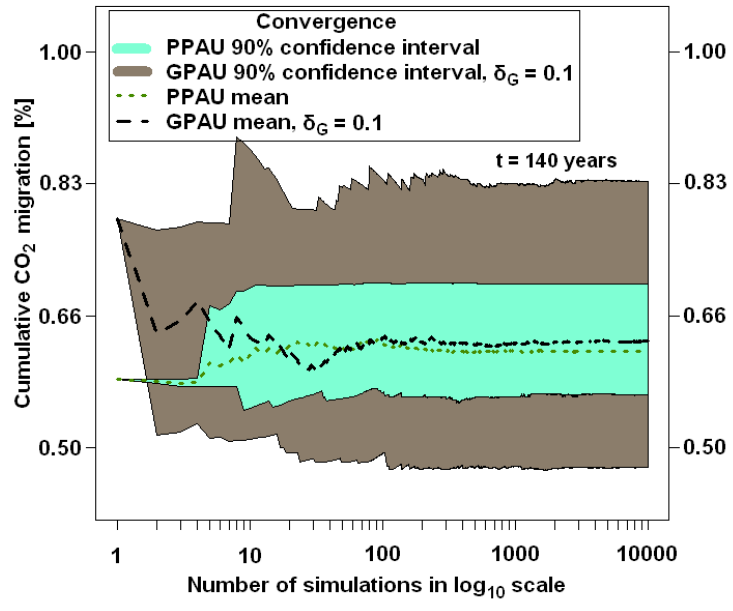

Fig. 9 Convergence analysis of probabilistic solver

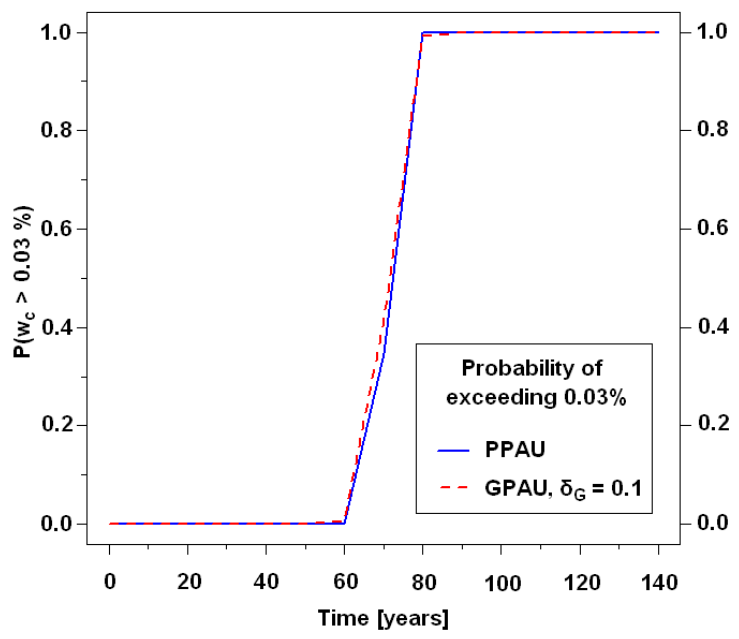

Fig. 10 Probability of exceeding a critical threshold of cumulative $\mathrm{CO}_{2}$ migration in surface

with respect to the level of model uncertainties. Therefore, a sensitivity of the model output values regarding the parameter $\delta_{\mathbb{G}}$ is presented in this section for three values $0.10,0.20$ and 0.40 . We then analyze the sensitivity of $P_{f}$ with respect to $\delta_{\mathbb{G}}$, corresponding to a range of values defined for the critical threshold $w_{c}$. Figure 11 displays the evolution of the confidence regions (quantiles $5 \%$ and $95 \%$ ) as a function of parameters $\delta_{\mathbb{G}}$ for $\mathrm{CO}_{2}$ migration from the reservoir towards the surface for the two probabilistic approaches. The results of the mean computational model, obtained in Section 7.2.1, are also presented in the same figure (nominal model). We observe that the width of the confidence region increases with $\delta_{\mathbb{G}}$. For example, for $\delta_{\mathbb{G}}=0.40$ and at $t=140$ years, the confidence interval is $[0.04 \% ; 1.53 \%]$ calculated by the GPAU which is 10 times larger than the confidence interval $[0.57 \% ; 0.71 \%]$ calculated by the 


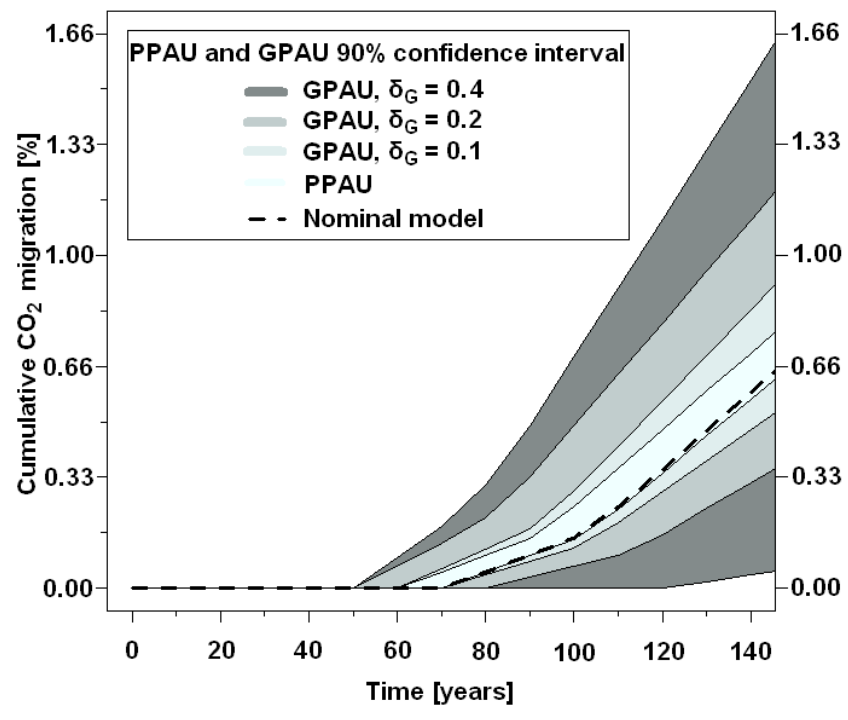

Fig. 11 Confidence region with a probability level $P_{c}=90 \%$ of the cumulative $\mathrm{CO}_{2}$ migration in surface for different level of uncertainties

PPAU. The mean computational model detects $\mathrm{CO}_{2}$ migration in surface starting from $t=70$ years, while the probabilistic approach detects $\mathrm{CO}_{2}$ migration starting from $t=50$ years for $\delta_{\mathbb{G}}=0.40$ or 0.20 . In order
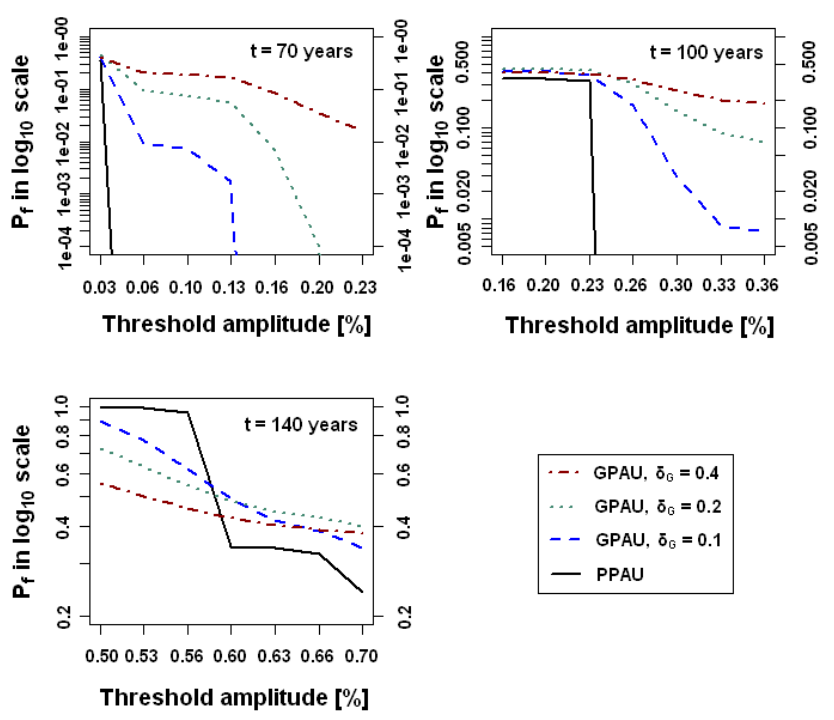

Fig. 12 Probability of exceeding a critical threshold range in surface at $t=70,100$ and 140 years for both probabilistic approaches $\left(\delta_{\mathbb{G}}=0.10,0.20\right.$ and 0.40 for GPAU). Zero values in $y$-axis are not represented for some points of both approaches, PPAU curve at $t=70$ and 100 years and GPAU curve at $t=70$ years, when $\delta_{\mathbb{G}}=0.10$ and 0.20 .

to observe more precisely the degree of sensitivity of $P_{f}$ with respect to $\delta_{\mathbb{G}}$, Fig. 12 displays the correspon- dence between a range of values of a critical threshold and $P_{f}$ at three times, $t=70,100$ and 140 years. For a given time, the range of values of the critical threshold has arbitrarily been defined on the basis of the maximum and the minimum values for the two probabilistic approaches. Figure 12 also shows two interesting aspects for the range of values corresponding to the critical threshold, at $t=70$ and 100 years: (a) concerning the PPAU, as its confidence region is smaller compared to the GPAU, it is less conservative than the GPAU as soon as critical threshold increases, that is to say, the PPAU evaluates early $P_{f}$ values as zero than the GPAU; (b) generally, the GPAU allows us to evaluate more important values for $P_{f}$ (for the range of values of the critical threshold) than the PPAU because its confidence region is larger than the PPAU. The calculated values of $P_{f}$ increase with $\delta_{\mathbb{G}}$, but it seems that $P_{f}$ values are closer to each other for $\delta_{\mathbb{G}}=0.20$ and 0.40 .

At $t=140$ years, according to an increment of the critical threshold, the value of $P_{f}$ calculated by the GPAU may be lower than that obtained by the PPAU. However, the critical threshold is important because, as it can be observed in Fig. 12, we can see the opposite for the rightmost values, i.e., the value of $P_{f}$ obtained with the PPAU may be lower than that obtained by the GPAU. It should be noted that the computed $P_{f}$ for the three values of $\delta_{\mathbb{G}}$ are closer to each other for the rightmost values of critical threshold.

In summary, for values of $\delta_{\mathbb{G}} \geq 0.20$, it could be observed at early years, when CO2 migration is detected (starting from $t=70$ years), the calculated values of $P_{f}$ are closer to each other. On the other hand, as a function of the increments of time and of the critical threshold values, $\delta_{\mathbb{G}}$ does not seem to have a strong influence on the calculated values of $P_{f}$. However, it should be noted that it is important to well define the critical threshold. The value of $\delta_{\mathbb{G}}$ cannot directly be determined because experimental data are not available. Based on available data, in the context of a real case, it could be considered a value of $\delta_{\mathbb{G}}=0.20$ in order to model the uncertainties introduced by modeling errors.

\section{Conclusions}

In geologic reservoirs, the long-term safety and effective storage of $\mathrm{CO}_{2}$ is of paramount importance for the acceptance of this technological solution with authorities and public. However, the predictions of the long-term safety of the potential storage sites involve a significant number of uncertainties due to their inherent variability and randomness. It is therefore essential to intro- 
duce robust predictive approaches with respect to uncertainties. In this paper, a robustness analysis has been presented for a computational model which predicts the performance and the risks associated with well integrity on long term . A simplified model is introduced for which each geological formation along the vertical axis of the well is modeled by a homogeneous medium. The mean computational model then combines porous media flow modeling and degradation models. The results obtained with the mean computational model are deterministic and are compared to the results obtained with the probabilistic model of both the system-parameter uncertainties and the model uncertainties induced by modeling errors.

It has been shown that the uncertainties have a strong influence on the migration prediction of the amount of $\mathrm{CO}_{2}$ along the well from the reservoir of $\mathrm{CO}_{2}$. The width of confidence regions of the predictions are increasing with the level of model uncertainties. This proved that the sensitivity of the predictions must be analyzed with respect to the level $\delta_{\mathbb{G}}$ of model uncertainties and that the degree of robustness of the stochastic computational model can be assessed. Such a sensitivity analysis has been performed and, based on available data, in the context of a real case, one can consider that a value of $\delta_{\mathbb{G}}=0.20$ is appropriate in order to model the uncertainties introduced by modeling errors.

Acknowledgements This work was supported by both Conseil Général de Seine et Marne (RIXMOD project, pôle Advancity-Ville et Mobilité Durable, France) and Agence de l'Environnement et de la Maîtrise de l'Energie (ADEME, France)

\section{References}

1. André L., Azaroual M. \& Menjoz A., 2010, Numerical simulations of the thermal impact of supercritical $\mathrm{CO}_{2}$ injection on chemical reactivity in a carbonate saline reservoir. Transport in Porous Media, 82 (1):247-274.

2. Arnst M., Clouteau D., Chebli H., Othman R. \& Degrande G., 2006, A nonparametric probabilistic model for ground-borne vibrations in buildings, Probabilistic Engineering Mechanics, 21(1):18-34.

3. Arnst M., Clouteau D. \& Bonnet M., 2008, Inversion of probabilistic structural models using measured transfer functions, Computer Methods in Applied Mechanics and Engineering, 197(6-8):589-608.

4. Au S.K. \& Beck J. L., 2003, Important sampling in high dimensions, Structural Safety, 25(2):139-163.

5. Barlet-Gouédard V., Rimmelé G., Goffé B. \& Porcherie O., 2007, Well technologies for $\mathrm{CO}_{2}$ geological storage: $\mathrm{CO}_{2}$-resistant cement, Oil and Gas Science and Technology, 62 (3):325-334.

6. Batou A., Soize C. \& Corus M., 2011, Experimental identification of an uncertain computational dynamical model representing a family of structures, Computer and Structures, 89(13-14):1440-1448.
7. Bear J. \& Verruijt A., 1987, Modeling Groundwater Flow and Pollution, D. Reidel Publishing Company.

8. Bear J. \& Bachmat Y., 1990, Introduction to Modeling of Transport Phenomena in Porous Media, Kluwer Academic Publishers.

9. Breysse D. \& Gérard B., 1997, Modelling of permeability in cement-based materials: Part 1-Uncracked medium, Cement and Concrete Research, 27(5):761-775.

10. Cailly B., Le Thiez P., Egermann P., Audibert A., VidalGilbert S. \& Longaygue X., 2005, Geological storage of $\mathrm{CO}_{2}$ : A state-of-the-art of injection processes and technologies. Oil and Gas Science and Technology, 60 (3):517-525.

11. Chebli H. \& Soize C., 2004, Experimental validation of a nonparametric probabilistic model of non homogeneous uncertainties for dynamical systems, Journal of the Acoustical Society of America, 115(2):697-705.

12. Flugge S., 1960, Principles of Classical Mechanics and Field Theory, Springer-Verlag, Berlin.

13. Gaus I., 2010, Role and impact of $\mathrm{CO}_{2}$-rock interactions during $\mathrm{CO}_{2}$ storage in sedimentary rocks, International Journal of Greenhouse Gas Control, 4(1):73-89.

14. Ghanem R. \& Spanos P. D., 1991, Stochastic Finite Elements : A Spectral Approach, Springer, New York.

15. Helmig R., 1997, Multiphase Flow and Transport Processes in the Subsurface: A Contribution to the Modeling of Hydrosystems, Springer-verlag, Berlin.

16. Houdu E., Poupard O. \& Meyer V., 2008, Supercritical $\mathrm{CO}_{2}$ leakage modelling for well integrity in geological storage project, proceedings of the 2008 International COMSOL Conference, 1-4 November 2008, Hannover, Germany, ISBN 978-0-9766792-3-3

17. Jaynes E. T., 1957, Information theory and statistical mechanics, Physical Review, 106(4), 620-630 and 108(2), 171-190.

18. Kaipio J. \& Somersalo E., 2005, Statistical ans Computational Inverse Problems, Springer-Verlag, New York.

19. Kalos M. H. \& Whitlock P. A., 1986, Monte Carlo Methods, Volume 1 : Basics, John Wiley and Sons, Chichester.

20. Kamali S., 2003, Comportement et simulation des matériaux cimentaires en environnements agressifs : lixiviation et température, Thèse de doctorat ( $\mathrm{PhD}$ Thesis), LMT, Ecole Normale Supérieure de Cachan, Cachan, France.

21. Kamali S., Gérard B. \& Moranville M., 2003, Modelling the leaching kinetics of cement-based materials - influence of materials and environment, Cement \& Concrete Composites, 25:451-458.

22. Kapur J. N. \& Kesavan H. K., 1992, Entropy Optimization Principles with Applications, Academic Press, San Diego.

23. Le Guen Y., Meyer V., Poupard O., Houdu E. \& Chammas R., 2009, A risk-based approach for well integrity management over long term in a $\mathrm{CO} 2$ geological storage project, SPE Asia Pacific Oil and Gas Conference and Exhibition - SPE paper n122510-PP, 4-6 August 2009, Jakarta, Indonesia, ISBN:978-1-55563-259-5

24. Mehta M. L., 1991, Random Matrices, Revised and Enlarged Second Edition, Academic Press, New York.

25. Nordboiten J.M., Kavetski D., Celia M.A. \& Bachu S., 2009, Model for $\mathrm{CO}_{2}$ leakage including multiple geological layers and multiple leaky wells. Environmental Science and Technology, 43 (3):743-749.

26. Pradlwarter H. J. \& Schueller G. I., 1997, On advanced Monte Carlo simulation procedures in stochastic structural dynamics, International Journal of Non-Linear Mechanics, 32(4): 735-744. 
27. Rubinstein R.Y. \& Kroese D. P., 2008, Simulation and the Monte Carlo Method, Second Edition, John Wiley \& Sons, New York.

28. Serfling R. J., 1980, Approximation Theorems of Mathematical Statistics, John Wiley and Sons, New York.

29. Schueller G. I., 2009, Efficient Monte Carlo simulation procedures in structural uncertainty and reliability analysis - recent advances, Structural Engineering and Mechanics, 32(1):1-20.

30. Shannon C. E., 1948, A mathematical theory of communication, Bell System Tech. J., 27: 379-423. and 623-659.

31. Schaap M.G., Leij F.J., 2000, Improved prediction of unsaturated hydraulic conductivity with the Mualem-van Genuchten model, Soil Science Society of America Journal, 64(3):843-851.

32. Shi J.-Q., Durucan S. \& Fujioka M., 2008, A reservoir simulation study of $\mathrm{CO}_{2}$ injection and $\mathrm{N} 2$ flooding at the Ishikari coalfield $\mathrm{CO}_{2}$ storage pilot project, Japan, International Journal of Greenhouse Gas Control, 2(1):47-57.

33. Soize C., 2000, A nonparametric model of random uncertainties on reduced matrix model in structural dynamics, Probabilistic Engineering Mechanics, 15(3):277-294.

34. Soize C., 2005, Random matrix theory for modeling uncertainties in computational mechanics, Computer Methods in Applied Mechanics and Engineering, 194(1216):1333-1366

35. Soize C., 2008, Construction of probability distributions in high dimension using the maximum entropy principle. Applications to stochastic processes, random fields and random matrices, International Journal for Numerical Methods in Engineering, 76(10): 1583-1611.

36. Soize C., Capiez-Lernout E., Durand J.-F. Fernandez C. \& Gagliardini L., 2008, Probabilistic model identification of uncertainties in computational models for dynamical systems and experimental validation, Computer Methods in Applied Mechanics and Engineering, 198(1):150-163.

37. Soize C., 2010, Generalized Probabilistic approach of uncertainties in computational dynamics using random matrices and polynomial chaos decompositions, International Journal for Numerical Methods in Engineering, 81(8):939-970.

38. Soize C., 2012, Stochastic Models of Uncertainties in Computational Mechanics, Lecture Notes in Mechanics, Number 3 (Ed. R. Ghanem), Engineering Mechanics Institute (EMI) of the American Society of Civil Engineers (ASCE), Reston, VA, USA.

39. Spall J.C., 2003, Introduction to Stochastic Search and Optimization, John Wiley and Sons, Hoboken, New Jersey.

40. Tanikawa W. \& Shimamoto T., 2006, Klinkenberg effect for gas permeability and its comparison to water permeability for porous sedimentary rocks, Hydrol. Earth Syst. Sci. Discuss., 3:1315-1338, doi:10.5194/hessd-31315-2006.

41. Tarantola A., 2005, Inverse Problem Theory and Methods for Model Parameter Estimation, SIAM, Philadelphia.

\section{Appendix}


Table 1 Initial and boundary conditions, fluid characteristics and physical parameters of the abandoned well

\begin{tabular}{|c|c|}
\hline Initial conditions at $t=0$ & Values \\
\hline $\begin{array}{l}\text { Cement sheaths and plugs saturation } \\
\text { System pressure }\end{array}$ & 1 Hydrostatic pressure \\
\hline Boundary conditions & Values \\
\hline $\begin{array}{l}\mathrm{CO}_{2} \text { reservoir pressure } \\
\text { Surface pressure } \\
\text { Surface temperature } \\
\text { Thermal gradient }\end{array}$ & $\begin{array}{l}385 \mathrm{bar} \\
1 \mathrm{bar} \\
20^{\circ} \mathrm{C} \\
2.5^{\circ} \mathrm{C} / 100 \mathrm{~m}\end{array}$ \\
\hline Fluid characteristics & Values \\
\hline $\begin{array}{l}\text { Water density } \\
\text { Water viscosity } \\
\text { Water leaching velocity } \\
\text { Water generalized corrosion } \\
\text { Water pitting corrosion } \\
\mathrm{CO}_{2} \text { leaching velocity } \\
\mathrm{CO}_{2} \text { degradation factor } \\
\mathrm{CO}_{2} \text { generalized corrosion } \\
\mathrm{CO}_{2} \text { pitting corrosion } \\
\text { Flow leaching velocity of geologic formations } \\
\text { Degradation factor of geologic formations } \\
\text { Flow generalized corrosion of geologic formations } \\
\text { Flow pitting corrosion of geologic formations } \\
\end{array}$ & $\begin{array}{l}1000 \mathrm{~kg} / \mathrm{m}^{3} \\
650 \times 10^{-6} \text { Pa.s } \\
0 \mathrm{~mm} / \text { (year }^{0.5} \\
0 \mathrm{~mm} / \text { year } \\
0.1 \mathrm{~mm} / \text { year } \\
1 \mathrm{~mm} / \text { year }^{0.5} \\
10 \\
2 \mathrm{~mm} / \text { year } \\
0 \\
0.1 \mathrm{~mm} /(\text { year })^{0.5} \\
10 \\
0.2 \mathrm{~mm} / \text { year, except F7: } 2 \mathrm{~mm} / \text { year } \\
0.5 \mathrm{~mm} / \text { year, except F7: } 0 \\
\end{array}$ \\
\hline Physical parameters, cement sheaths & Values \\
\hline $\begin{array}{l}\text { Porosity } \\
\text { Initial axial and radial permeability } \\
\text { Capillary pressure head } \\
\text { Water residual saturation }\end{array}$ & $\begin{array}{l}0.35 \\
10 \mathrm{mD} \\
1 \\
0.2\end{array}$ \\
\hline Physical parameters, cement plugs & Values \\
\hline $\begin{array}{l}\text { Porosity } \\
\text { Initial axial and radial permeability } \\
\text { Capillary pressure head } \\
\text { Water residual saturation }\end{array}$ & $\begin{array}{l}0.25 \\
0.1 \mathrm{mD} \\
1 \\
0.2\end{array}$ \\
\hline Physical parameters, aquifer, F3 & Values \\
\hline $\begin{array}{l}\text { Porosity } \\
\text { Initial radial permeability } \\
\text { Initial axial permeability } \\
\text { Capillary pressure head } \\
\text { Water residual saturation }\end{array}$ & $\begin{array}{l}0.2 \\
44 \mathrm{mD} \\
10^{3} \mathrm{mD} \\
1 \\
0.2\end{array}$ \\
\hline Physical parameters, reservoir, F7 & Values \\
\hline $\begin{array}{l}\text { Porosity } \\
\text { Initial radial permeability } \\
\text { Initial axial permeability } \\
\text { Capillary pressure head } \\
\text { Water residual saturation }\end{array}$ & $\begin{array}{l}0.2 \\
40 \mathrm{mD} \\
40 \mathrm{mD} \\
1 \\
0.2 \\
\end{array}$ \\
\hline
\end{tabular}


Table 2 Values of the parameters of the probability distributions for the uncertain parameters of the system

\begin{tabular}{|c|c|c|}
\hline Cement item & Physical parameter & Data \\
\hline Cement sheaths & $\begin{array}{l}\text { Axial permeability }[\mathrm{mD}] \\
\text { Radial permeability }[\mathrm{mD}] \\
\text { Capillary pressure head [bar] } \\
\text { Water residual saturation } \\
\text { Axial permeability }[\mathrm{mD}] \\
\text { Radial permeability }[\mathrm{mD}] \\
\text { Capillary pressure head [bar] } \\
\text { Water residual saturation }\end{array}$ & $\begin{array}{l}\text { Min }=1, \operatorname{Max}=100, \mu=37, \sigma=22 \\
\text { Min }=1, \operatorname{Max}=100, \quad \mu=37, \sigma=22 \\
\text { Min }=1, \operatorname{Max}=10^{5}, \quad \mu=33334, \sigma=23570 \\
\text { Min }=0.2, \operatorname{Max}=0.4, \quad \mu=0.27, \sigma=0.05 \\
\text { Min }=0.01, \operatorname{Max}=0.1, \quad \mu=0.07, \sigma=0.02 \\
\text { Min }=0.01, \operatorname{Max}=0.1, \quad \mu=0.07, \sigma=0.02 \\
\text { Min }=1, \operatorname{Max}=10^{5}, \quad \mu=33334, \sigma=23570 \\
\text { Min }=0.2, \operatorname{Max}=0.4, \quad \mu=0.27, \sigma=0.05\end{array}$ \\
\hline \multicolumn{3}{|l|}{ Geological formation } \\
\hline Aquifer F3 & $\begin{array}{l}\text { Axial permeability }[\mathrm{mD}] \\
\text { Radial permeability }[\mathrm{mD}] \\
\text { Capillary pressure head [bar] } \\
\text { Porosity } \\
\text { Water residual saturation } \\
\text { Axial permeability }[\mathrm{mD}] \\
\text { Radial permeability }[\mathrm{mD}] \\
\text { Capillary pressure head [bar] } \\
\text { Porosity } \\
\text { Water residual saturation }\end{array}$ & $\begin{array}{l}\operatorname{Min}=10, \operatorname{Max}=10^{3}, \mu=670, \sigma=233 \\
\operatorname{Min}=0.44, \operatorname{Max}=44, \mu=29, \sigma=10 \\
\operatorname{Min}=1, \operatorname{Max}=10^{5}, \mu=33334, \sigma=23570 \\
\operatorname{Min}=0, \operatorname{Max}=0.2 \mu=0.13, \sigma=0.05 \\
\operatorname{Min}=0.01, \operatorname{Max}=0.2, \mu=0.14, \sigma=0.04 \\
\operatorname{Min}=1, \operatorname{Max}=100, \mu=47, \sigma=20 \\
\operatorname{Min}=1, \operatorname{Max}=100, \mu=47, \sigma=20 \\
\operatorname{Min}=1, \operatorname{Max}=10^{5}, \mu=33334, \sigma=23570 \\
\operatorname{Min}=0, \operatorname{Max}=0.2, \mu=0.13, \sigma=0.05 \\
\operatorname{Min}=0.2, \operatorname{Max}=0.4, \mu=0.27, \sigma=0.05\end{array}$ \\
\hline \multicolumn{3}{|l|}{ Degradation model } \\
\hline Water & $\begin{array}{l}\text { leaching velocity }\left[\mathrm{mm} / \text { year }^{1 / 2}\right] \\
\text { generalized corrosion }[\mathrm{mm} / \text { year}] \\
\text { pitting corrosion }[\mathrm{mm} / \text { year] } \\
\text { leaching velocity }\left[\mathrm{mm} / \text { year }^{1 / 2}\right] \\
\text { degradation factor } \\
\text { generalized corrosion }[\mathrm{mm} / \text { year] } \\
\text { pitting corrosion }[\mathrm{mm} / \text { year] }\end{array}$ & $\begin{array}{l}\operatorname{Min}=0.001, \operatorname{Max}=0.1, \mu=0.04, \sigma=0.02 \\
\operatorname{Min}=0.001, \operatorname{Max}=0.1, \mu=0.00533, \sigma=0.00184 \\
\operatorname{Min}==0.002, \operatorname{Max}=0.02, \mu=0.01, \sigma=0.00368 \\
\operatorname{Min}=0.1, \operatorname{Max}=2, \mu=1, \sigma=0.4 \\
\operatorname{Min}=1, \operatorname{Max}=10, \mu=5.33, \sigma=1.84 \\
\operatorname{Min}=1, \operatorname{Max}=5, \mu=3, \sigma=0.82 \\
0\end{array}$ \\
\hline Geological formations & $\begin{array}{l}\text { leaching velocity }\left[\mathrm{mm} / \text { year }^{1 / 2}\right] \\
\text { degradation factor } \\
\text { generalized corrosion }[\mathrm{mm} / \text { year}]\end{array}$ & $\begin{array}{l}\operatorname{Min}=0.1, \operatorname{Max}=0.5, \mu=0.3, \sigma=0.08 \\
\text { Min }=1, \operatorname{Max}=10, \mu=5.33, \sigma=1.84 \\
\text { Min }=0.1, \operatorname{Max}=0.5, \mu=0.3, \sigma=0.08 \\
\text { except for F7: } \\
\text { Min }=1, \operatorname{Max}=5, \mu=3, \sigma=0.82 \\
\text { Min }=0.2, \operatorname{Max}=1, \mu=0.6, \sigma=0.16 \\
\text { except for F7: } \\
0\end{array}$ \\
\hline
\end{tabular}

